\title{
The Japan Society for Surgical Infection: guidelines for the prevention, detection, and management of gastroenterological surgical site infection, 2018
}

\author{
Hiroki Ohge ${ }^{1} \cdot$ Toshihiko Mayumi $^{2} \cdot$ Seiji Haji $^{3}$ - Yuichi Kitagawa ${ }^{4} \cdot$ Masahiro Kobayashi $^{5} \cdot$ Motomu Kobayashi $^{6}$. \\ Toru Mizuguchi ${ }^{7} \cdot$ Yasuhiko Mohri $^{8} \cdot$ Fumie Sakamoto $^{9} \cdot$ Junzo Shimizu $^{10} \cdot$ Katsunori Suzuki $^{11} \cdot$ Motoi Uchino $^{12}$. \\ Chizuru Yamashita $^{13} \cdot$ Masahiro Yoshida $^{14} \cdot$ Koichi Hirata $^{15}$. Yoshinobu Sumiyama ${ }^{16}$. Shinya Kusachi ${ }^{17} \cdot$ The $^{12}$ \\ Committee for Gastroenterological Surgical Site Infection Guidelines, the Japan Society for Surgical Infection
}

Accepted: 30 October 2020 / Published online: 15 December 2020

(c) The Author(s) 2020

\begin{abstract}
Background The guidelines for the prevention, detection, and management of gastroenterological surgical site infections (SSIs) were published in Japanese by the Japan Society for Surgical Infection in 2018. This is a summary of these guidelines for medical professionals worldwide.

Methods We conducted a systematic review and comprehensive evaluation of the evidence for diagnosis and treatment of gastroenterological SSIs, based on the concepts of the Grading of Recommendations Assessment, Development and Evaluation (GRADE) system. The strength of recommendations was graded and voted using the Delphi method and the nominal group technique. Modifications were made to the guidelines in response to feedback from the general public and relevant medical societies.

Results There were 44 questions prepared in seven subject areas, for which 51 recommendations were made. The seven subject areas were: definition and etiology, diagnosis, preoperative management, prophylactic antibiotics, intraoperative management, perioperative management, and wound management. According to the GRADE system, we evaluated the body of evidence for each clinical question. Based on the results of the meta-analysis, recommendations were graded using the Delphi method to generate useful information. The final version of the recommendations was published in 2018, in Japanese. Conclusions The Japanese Guidelines for the prevention, detection, and management of gastroenterological SSI were published in 2018 to provide useful information for clinicians and improve the clinical outcome of patients.
\end{abstract}

Keywords Surgical site infection · Guidelines · Antibiotics · Drain

The Japan Society for Surgical Infection: Guidelines for the Prevention, Detection, and Management of Gastroenterological Surgical Site Infection Guidelines, 2018, were published in Japanese in 2018. We share these guidelines in English with healthcare professionals and the general public around the world to improve medical practice and patient outcomes.

Electronic supplementary material The online version of this article (https://doi.org/10.1007/s00595-020-02181-6) contains supplementary material, which is available to authorized users.

Hiroki Ohge

ohge@hiroshima-u.ac.jp

Extended author information available on the last page of the article

\section{Introduction}

The guidelines for the prevention, detection, and management of gastroenterological surgical site infections (SSIs) were published in 2018, in Japanese, by the Japan Society for Surgical Infection ${ }^{(1)}$. This is a summary of these guidelines in English for medical professionals around the world.

\section{Purpose of the guidelines}

SSIs are the main focus of the Japan Society for Surgical Infection. The Society conducted three randomized controlled trials, on total gastrectomy, hepatectomy, and colectomy, to evaluate the duration of perioperative preventive 
antibiotic administration ${ }^{(1)}$. Several SSI guidelines have been revised or created; however, these are international guidelines and clinical situations differ among countries ${ }^{(2-4)}$. Therefore, we constructed the Japanese Guidelines for the prevention, detection, and management of gastroenterological SSIs to inform medical staff and improve patients' outcomes.

\section{Methods used to construct the guidelines}

The Committee for Gastroenterological Surgical Site Infection Guidelines within the Japan Society for Surgical Infection was formed in April, 2016. After studying the preparation methods for the guidelines and the Grading of Recommendations Assessment, Development and Evaluation (GRADE) system, the members devised Clinical
Questions (CQ) and performed a systematic review using keywords in PubMed and Japana Centra Revuo Medicina Web (Ichushi-Web) between January, 2000 and March, 2016. Table 1 presents the findings of evidence assessed by following the procedures ${ }^{(2-4)}$. The strength of recommendations was graded with reference to the quality of the evidence, the preferences of the patient, the risks and benefits, and cost estimates. In terms of consensus-building, a vote was taken using the Delphi method and the nominal group technique (NGT), and issues with a support rate of more than $70 \%$ were approved. Table 2 shows the grading of the recommendations.

The proposal for the guidelines received comments from the public and feedback from members of the Japan Society for Surgical Infection, the Japan Surgical Society, the Japanese Society of Gastroenterology Surgery, the Japanese Society of Hepato-Biliary-Pancreatic Surgery, the Japanese

Table 1 Quality of evidence ${ }^{(5)}$

Comprehensive assessment of publications by outcomes and design

(1) Initial assessment: assessment by each study design group

A: SR (systematic review), MA (meta-analysis), RCT (randomized controlled trial)

C: OS (observational study)

D: CS (case series, case report)

(2) Assessment of the presence/absence of factors that decrease evidence levels

Risk of bias in study quality

Inconsistent results (different conclusions in various papers)

Indirect evidence (inconsistency between content within a paper and the CQ, or content in a paper which

is not directly applicable to clinical use)

Inaccurate data (insufficient number of cases)

High probability of publication bias (only favorable results reported)

(3) Assessment of the presence/absence of factors that increase evidence levels Profound effects with no confounders (profound effects expected for all cases)

Dose-response gradient (more profound effects expected with increased dosage)

Possible confounders that diminish actual effects

Comprehensive assessment: overall quality of evidence across outcomes was assessed and graded as A (high), B (moderate), C (low), or D (very low)

Table 2 Strength of recommendations

\begin{tabular}{ll}
\hline $\begin{array}{l}\text { Strength of recommenda- } \\
\text { tions }\end{array}$ & Contents \\
\hline Consensus & $\begin{array}{l}\text { Self-evident truth, ethically impossible to perform a high quality clinical study } \\
\text { Strongly recommended to perform } \\
\text { Recommended to perform } \\
\text { Evidence is moderate or strong, although evidence of effectiveness is sparse } \\
\text { Evidence is sparse, but may be considered in the decision to perform } \\
\text { Effectiveness can possibly be expected }\end{array}$ \\
$2 \mathrm{~b}$ & $\begin{array}{l}\text { Scientific evidence is not sufficient, so clear recommendation cannot be made } \\
\text { Evidence is not sufficient to support or deny effectiveness } \\
3\end{array}$ \\
& $\begin{array}{l}\text { Recommended not to perform } \\
\text { Harm or risk can possibly exceed benefit } \\
\text { Strongly recommended not to perform } \\
\text { There is evidence to deny effectiveness (to show harm) }\end{array}$ \\
&
\end{tabular}


Table 3 Summary of recommendations

1. Definition, epidemiology, and risk factors of SSI

(1) Surgical site infection is defined as an infection that involves the skin and subcutaneous tissue of the incision (superficial incisional) and/or the deep soft tissue (for example, fascia, muscle) of the incision (deep incisional) and/or any part of the anatomy other than the incision that was opened or manipulated during an operation (organ/space)

(2) The incidence of surgical site infection after gastrointestinal surgery was $9.6 \%$ according to the Japan Nosocomial Infections surveillance. The incidence of SSI is highest after esophageal surgery, followed by rectal surgery and hepatobiliary surgery

(3) The risk factors for surgical site infection are ASA, wound class, prolonged operation time, diabetes, obesity, hyponutritional status, history of smoking, and intraoperative blood transfusion

2. Diagnosis criteria, surveillance, and causal bacterium of SSI

(1) The criteria suggested by the Centers for Disease Control and Prevention (CDC)/National Healthcare Saftety Netowrk (NHSN) are used for the diagnosis of SSI. In Japan, some of these criteria have been modified slightly

(2) Some reports suggest that the incidence of SSI after gastrointestinal surgery decreases with surveillance. Surveillance is necessary to assess the true incidence of SSI (D, Consensus)

(3) Surveillance for more than 30 days after surgery is necessary, including for discharged patients (C, Consensus). It is preferable that the surveillance include many examination methods such as bacterial culture in combination with surveillance by an infection control team (ICT) for evaluation (D, Consensus)

(4) In Japan, a surveillance system such as JANIS and JHAIS report the latest detection methods. Reference to these data for each surgical procedure is recommended

3. Preoperative management of SSI

(1) In digestive surgery, the incidence of SSI in patients with known nasal carriage of S. aureus may be high

(2) Preoperative decolonization may be useful for preventing SSI in patients who are known nasal carriers of S. aureus (C, 2a). However, universal decolonization without screening is not recommended, to prevent the spread of resistance (B, 4). Candidacy for screening of $S$. aureus carriage should be determined based on the local epidemiology in the hospital, the patient's risk factors for S. aureus infection, and the surgical procedure to be performed

(3) Although it may be desirable to give effective antibiotic prophylaxis to patients carrying resistant bacteria, there is no clear foundation to recommend it $(\mathrm{D}, 3)$

(4) Since patients with preoperative malnutrition who undergo digestive operations have a high incidence of SSI, the committee recommends that the malnutrition status should be improved before surgery $(\mathrm{B}, 2 \mathrm{a})$

(5) It is not effective to administer enhanced nutritional formulas before surgery for the purpose of preventing SSI in non-malnourished patients who undergo digestive operations $(\mathrm{B}, 3)$

(6) Preoperative smoking is a high-risk factor for SSI (B). Patients who discontinue smoking for 1 month before surgery may decrease their risk of SSI (C, 2a)

(7) Preoperative regular alcohol consumption is a risk factor for SSI (C). The effectiveness of abstinence from alcohol to prevent SSI is not clearly indicated, but we suggest preoperative abstinence (D, 2b)

(8) Long-term or high-dose steroids are risk factors for SSI (C). The administration of immunomodulators and biologics before surgery is not a risk factor for SSI (C). However, the effect of reducing these drugs on SSI incidence has not been studied. Reduction or withdrawal of these drugs should be planned based on the original disease (D)

(9) Preoperative mechanical bowel preparation (MBP) alone does not appear to have a preventive effect on SSI (A). However, MBP with oral antibiotics added (OAMBP) is recommended since it may have a preventative effect on SSI (B, 2a)

(10) Preoperative cleansing of the skin with chlorhexidine gluconate has no effect on preventing SSI $(\mathrm{B}, 4)$

(11) It has been recommended to shave to prevent SSI, and not to do so (A, 5). There is no difference in the incidence of SSI between clipper hair removal, no hair removal, or using hair depilation cream (B)

4. Prophylactic antibiotics

(1) Treatment with prophylactic antibiotics is considered beneficial in gastrointestinal surgery because of its effectiveness in the prevention of SSIs after laparoscopic cholecystectomy (A, 2a) and inguinal hernia surgery (B, 2a)

(2) Although evidence is limited, administration within 60 min before the surgical incision is preferred (D, 2b)

(3) No high-quality studies have shown that the intraoperative re-administration of prophylactic antibiotics reduces SSI incidence, and the utility of readministration is not known. Therefore, there is no basis for recommending when re-administration is appropriate (C)

(4) In patients undergoing elective gastrectomy for gastric cancer when prophylactic antibiotics were administered only before surgery (including patients given additional intraoperative treatment when surgery exceeded $3 \mathrm{~h}$ ), there was no increase in SSI incidence compared with those who also received prophylactic antibiotic treatment after surgery. For this reason, only administration before surgery (including additional intraoperative treatment when surgery exceeds $3 \mathrm{~h}$ ) is recommended $(\mathrm{B}, 2 \mathrm{a})$. Evidence of the duration of prophylactic antibiotic treatment in elective colectomy for colorectal cancer is limited, and at this point, the difference in the benefit of administration only before surgery (including additional intraoperative treatment when surgery exceeds $3 \mathrm{~h}$ ) and administration both before and after surgery is unknown (C, 3). Note that this analysis focuses mainly on laparotomy data, and laparoscopic surgery is a topic for future investigation

5. Intraoperative management

(1) Surgical hand scrubbing and rubbing exhibit are equally effective for SSI prevention. Either method is acceptable but should be performed appropriately (A, no recommendation) 
Table 3 (continued)

(2) The panel recommends alcohol-based antiseptic solutions with chlorhexidine gluconate for surgical site skin preparation for patients undergoing gastrointestinal surgical procedures $(\mathrm{B}, 2 \mathrm{a})$

(3) The effectiveness of adhesive drapes in preventing SSI is unclear (C, 3)

(4) The use of wound protector devices, especially the double-ring wound protector device used in gastrointestinal surgical procedures, reduces the rate of SSI (A, 2a)

(5) We suggest the use of double-gloving during surgery to address safety concerns since glove perforation may cause occupational exposures, injuries, or infections $(\mathrm{A}, 2 \mathrm{~b})$

(6) The value of changing instruments during surgery for preventing SSI is unclear due to the lack of evidence; hence, we do not actively recommend this practice. However, it is recommended to change instruments to avoid the use of potentially dirty or contaminated surgical operations (D, 2b)(7) We recommend the use of antimicrobial-coated sutures for preventing SSI during digestive surgery (B, 2a)

(8) We recommend wound irrigation, especially with high pressure, for preventing SSI (C, 2a). However, we cannot provide a recommendation for wound irrigation with disinfectant, antibiotics, or electrolyzed acidic aqueous solution due to the lack of evidence (D, 3)

(9) We do not recommend peritoneal lavage for preventing SSI due to the lack of evidence (D, 3)

(10-1) Drain placement after surgery for gastric cancer did not show any benefit for SSI prevention. Drain placement is not necessary because mortality and complication rates are also low $(\mathrm{B}, 3)$

(10-2) Complications, SSI incidence and mortality are similar with or without drains after laparoscopic cholecystectomy, but the operation time was shortened with non-drainage. Therefore, drain placement is not required (A, 4)

(10-3) The absence of a drain after hepatectomy without biliary reconstruction tends to have a lower SSI rate, less ascites, and shorter hospitalization. Therefore, the committee recommended that drain placement after hepatectomy was unnecessary. $(\mathrm{A}, 4)$

(10-4) SSI after pancreatoduodenectomy tends to be higher in the no-drain group, and some studies have been discontinued due to increased mortality rates, so it is recommended to use a drain $(\mathrm{B}, 2 \mathrm{~b})$. As far as duration of the drain placement, the committee recommended that it be removed early according to the criteria for postoperative pancreatic juice and that patients should be selected carefully

(10-5) No drain is preferable after appendectomy for preventing SSI. Drain placement may increase the incidence of complications and mortality. Therefore, we do not recommend drain placement after appendectomy. $(\mathrm{B}, 4)$

(10-6) In colon surgery, drain placement is unnecessary in the prevention of SSI (A, 4). The clinical benefit of the drain placement is unclear, and it might be unnecessary. On the other hand, drain placement could be considered in specific cases when it might contribute to reducing severe complications (A, 3)

(10-7) Although subcutaneous drain placement may reduce the incidence of SSI, it is necessary to consider the indications for appropriate cases, methods, and duration. (B, 3)

(11-1) Subcutaneous suturing using absorbed materials is recommended. (B, 3)

(11-2) Continuous sutures tended to result in less wound dehiscence and fewer wound infections than interrupted sutures for subcutaneous suturing after gastroenterological surgery. Therefore, continuous sutures rather than interrupted sutures are recommended for subcutaneous suturing (B, 2a). In fascia closure, incidences of SSI and wound hernia did not differ between continuous sutures and interrupted sutures. Therefore, either method can be used (B, 3)

(11-3) Subcutaneous sutures using absorbable materials do not reduce the incidence of SSI versus skin closure using a stapler. However, it is recommended for cosmetic purposes and patient satisfaction (B, 2b)

(11-4) The rates of SSI and wound dehiscence associated with bioadhesivesfor primary wound closure were comparable to those of sutures alone. Bioadhesives may improve cosmetic results and shorten operation time in primary wound closure after laparoscopic surgery $(\mathrm{C}, 3)$

6. Perioperative management

(1) Implementation of an early recovery program is recommended to reduce the incidence of SSI in patients undergoing digestive surgery, as well as for shortening the length of hospital stay and accelerating the recovery of gut function (A, 2a). However, it remains unclear which components of the program are optimal for SSI prevention in various types of digestive surgery

(2) Preoperative carbohydrate loading does not prevent SSI after digestive surgery. Therefore, implementation of preoperative carbohydrate loading prevention is not recommended for SSI prevention $(\mathrm{A}, 3)$

(3) A blood glucose level of less than $150 \mathrm{mg} / \mathrm{dL}$ is desirable because strict blood glucose control during the postoperative period reduces the incidence of SSI significantly in digestive surgery patients with and those without diabetes mellitus (B, 2b). On the other hand, blood glucose should be monitored closely because of the inherent risk of a hypoglycemic event

(4) There are no guidelines on whether perioperative oral hygiene contributes to the prevention of SSI in gastrointestinal surgery because of the lack of evidence (D). On the other hand, perioperative oral care may help to prevent postoperative pneumonia after esophagectomy

(5) Intraoperative warming for maintaining normothermia is recommended for SSI prevention. (B, 2a)

(6) High oxygen concentrations $\left(\mathrm{FIO}_{2}\right.$ of 0.8$)$ during and within $2-6 \mathrm{~h}$ after colorectal surgery may reduce the risk of SSI (B, 3). However, high concentrations of oxygen also have adverse effects such as absorption atelectasis and oxygen toxicity. Furthermore, the safety of high oxygen concentrations during long operations is not supported. The indication for high $\mathrm{FIO}_{2}$ should be evaluated carefully

(7) Although early postoperative oral and enteral feeding does not reduce the risk of SSI (B), it is recommended because of other benefits such as shortening the hospital stay

7. Wound management

(1) It is preferable to use protective wound dressings for relatively large incisional wounds after abdominal surgery, rather than covering them with gauze (B, 2b)

(2) Although negative-pressure wound therapy at primary closure during abdominal surgery may reduce incisional SSI, the indications and costs need to be considered $(\mathrm{B}, 3)$ 
Association for Infectious Disease, and Takeo Nakayama of the Department of Health Informatics, Kyoto University, School of Public Health. The guidelines were modified in response to this feedback and finally published in 2018 . Table 3 lists the key recommendations.

To increase dissemination of the guidelines, they were also published as a small booklet, and were uploaded onto the homepage of the Japan Society for Surgical Infection and Medical Information Network Distribution Service (Minds). This is a summary of the Guidelines for the prevention, detection, and management of gastroenterological SSI published in Japanese by the Japan Society for Surgical Infection in 2018. References and a funnel plot of meta-analysis are provided in a Supplemental File.

\section{Conflict of Interest and revision of the guidelines}

The guidelines were supported only by the Japan Surgical Infection Society. The members of the Committee for Gastroenterological Surgical Site Infection Guidelines declared this conflict of interest to the society. Members who had a conflict with the CQs did not participate in casting their vote on the recommendation for the CQs. The guidelines will be revised in approximately 5 years.

\section{Preoperative management}

CQ 3-1: Is the incidence of SSI high in
preoperative nasal carriers of Staphylococcus
aureus?
Recommendations
In digestive surgery, the incidence of SSI in patients
with known nasal carriage of $S$. aureus may be high.
(c)

\section{Rationale}

The meta-analysis was conducted on seven observational studies $^{(5-11)}$. The incidence of $S$. aureus in SSI was significantly higher in nasal carriers of $S$. aureus undergoing digestive surgery (odds ratio [OR] 9.0, 95\% confidence interval [CI] 5.09-15.91) (Fig. 3-1). However, six of the seven studies included patients who were undergoing not only digestive surgery, but also other types of surgery ${ }^{(5,7-11)}$. Moreover, six of seven subjects were evaluated for the presence or absence of MRSA carriage only ${ }^{(5-10)}$.

CQ3-2: Does preoperative decolonization in
patients with nasal carriage of Staphylococcus
aureus prior to digestive surgery reduce
postoperative surgical site infections?
Recommendations
Preoperative decolonization may be useful for
preventing SSI in patients who are known nasal
carriers of $S$. aureus (C, 2 a). However, universal
decolonization without screening is not
recommended to prevent the spread of resistance (B,
4). Candidacy for the screening of $S$. aureus carriage
should be based on the local epidemiology in the
hospital, the patient's risk factors for $S$. aureus
infection, and the surgical procedure to be performed.

\section{Rationale}

Two meta-analyses were performed to evaluate the benefit of decolonization in patients with known nasal carriage of S. aureus and of universal decolonization in all preoperative patients. Two RCTs showed that decolonization in patients with nasal $S$. aureus carriage had significantly greater benefit than no treatment in reducing the $S$. aureus SSI rate (Fig. 3-2) ${ }^{(7,12)}$. There was no significant difference in mortality (Fig. 3-3). A prospective intervention cohort study also showed that the SSI rate in the decolonized group was not significantly higher than that of non-carriers (OR 0.8, 95\% CI 0.19-3.44) ${ }^{(13)}$. All subjects in the decolonization group had received preoperative intranasal mupirocin ointment with or without a combination of chlorhexidine gluconate body wash. Two subsequent RCTs showed that universal decolonization did not reduce the SSI incidence significantly (Fig. 3-4) ${ }^{(7,14)}$. On the other hand, in a historical control study the incidence of SSI was significantly lower with universal decolonization than without it ${ }^{(15)}$. However, the spread of mupirocin resistance by universal decolonization is an important issue. For this reason, the committee members decided not to recommend universal decolonization $(B, 4)$. 


\section{CQ3-3: Should we change perioperative} prophylaxis to prevent SSI in multidrug-resistant carriers of bacteria other than MRSA?

\section{Recommendations}

Although it may be desirable to use an effective antibiotic prophylaxis in patients carrying resistant bacteria, there is no clear foundation to recommend it. $(\mathrm{D}, 3)$

\section{CQ3-4: Is preoperative nutritional improvement useful for reducing the risk of SSI in malnourished patients? \\ Recommendations \\ Since patients with preoperative malnutrition, who undergo digestive operations, have a high incidence of SSI, the committee recommends that malnutrition be addressed before surgery. (B, 2a)}

\section{Rationale}

An analysis of six observational studies showed that the SSI rate in patients with preoperative malnutrition was higher than that in patients without malnutrition (OR 3.48, 95\% CI 2.57-4.71, $\mathrm{P}<0.00001$ ) (Fig. 3-5) ${ }^{(16-20)}$. The reports used the prognostic nutrition indicators of serum albumin levels, prealbumin levels, and weight loss, to identify patients with malnutrition. A subsequent meta-analysis, consisting of two $\operatorname{RCTs}^{(21,22)}$ and one observational study ${ }^{(17)}$ for SSI, revealed that nutrition improvement before surgery for patients with malnutrition reduced the incidence of SSI. The combined OR was 0.56 (95\% CI 0.37-0.84) for the RCTs (Fig. 3-6) and 0.25 (95\% CI $0.11-0.56)$ for the observational study. However, the methods and duration of appropriate nutrition interventions are unclear.
CQ3-5 : Does the administration of enhanced nutritional formulas reduce SSI in preoperative patients without malnutrition?

\section{Recommendations}

It is not effective to administer enhanced nutritional formulas before surgery for the purpose of preventing SSI in non-malnourished patients who undergo digestive operations $(\mathrm{B}, 3)$.

\section{Rationale}

Three RCTs and one prospective assignment study showed that preoperative immunonutrition does not reduce the rate of SSI significantly in patients without malnutrition (RR 0.63, 95\% CI 0.31-1.27) (Fig. 3-7). Moreover, preoperative immunonutrition did not result in significant improvement in terms of duration of hospital stay (Fig. 3-8) ${ }^{(23,24)}[1,4]$ and survival rates (Fig. 3-9) ${ }^{(22,23,25)}$. However, several studies have added immunomodulatory nutrition to regular meals, so the study design may not have been appropriate.

\section{CQ 3-6: Does preoperative smoking cessation} reduce SSI?

\section{Recommendations}

Preoperative smoking is a high-risk factor for SSI

(B). Patients who discontinue smoking for 1 month before surgery may decrease their risk of SSI (C, 2a).

\section{Rationale}

An $\mathrm{RCT}^{(26)}$ comparing SSI incidence in smokers with or without preoperative smoking cessation showed a tendency toward a decrease in the risk ratio (RR) of $0.48(95 \% \mathrm{CI}$ $0.2-1.16$ ), but no significant difference was observed. In the meta-analysis comparing SSI incidence rates between preoperative smokers and nonsmokers, preoperative smoking was significantly associated with an SSI risk, with an OR of $1.79(95 \% \text { CI } 1.59-1.94)^{(27-57)}$. 


\section{CQ3-7: Is preoperative abstinence from alcohol} effective for preventing SSI?

\section{Recommendations}

Preoperative regular alcohol consumption is a risk factor for SSI (C). The effectiveness of abstinence from alcohol for preventing SSI is not clearly indicated, but it is recommended (D, 2b).

\section{Rationale}

With respect to the incidence of SSI in relation to differences in alcohol consumption, the OR was 1.43 (95\% CI 1.10-1.85) in seven observational studies (Fig. 3-11), and heavy drinking was a significant risk factor for SSI ${ }^{(39,58-63)}$. A small RCT of preoperative abstinence in drinkers did not show a significant effect on SSI reduction (RR 0.972; $95 \%$ CI $0.70-1.35)^{(64)}$.

CQ3-8: Does reduction or withdrawal of
preoperative steroids or immunomodulators
reduce SSI?
Recommendations
Long-term or high-dose steroids are risk factors for
SSI (C), but the administration of
immunomodulators and biologics before surgery is
not a risk factor for SSI (C). However, the effect of a
reduction of these drugs on SSI incidence has not
been studied. Reduction or withdrawal of these drugs
should be planned based on the original disease (D).

\section{Rationale}

The administration of infliximab (IFX) has not been identified as a risk factor for SSI in patients with inflammatory

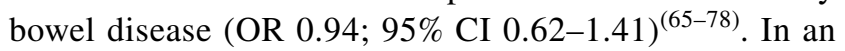
observational study by Ahn et al., the onset of postoperative infection, with or without long-term steroid administration, was examined in patients with inflammatory bowel disease. The steroid administration group had a significantly higher incidence of postoperative infectious complications (OR
5.83; 95\% CI 1.063-32.021) ${ }^{(79)}$. In a report by Miki et al. ${ }^{(80)}$, postoperative infectious complications were examined by dividing the preoperative steroid total dose of $12 \mathrm{~g}$ as the boundary into two groups of high dose and low dose. The low-dose group had significantly lower postoperative infectious complications than the high-dose group (OR 3.40; 95\% CI 1.172-9.862). Based on these results, long-term or highdose steroids are regarded as a risk factor for postoperative SSI incidence (C).

CQ3-9: Is bowel preparation useful for SSI prevention?

\section{Recommendations}

Preoperative mechanical bowel preparation (MBP) alone does not show a preventive effect on SSI (A). However, MBP with oral antibiotics added (OAMBP) is recommended since it may have a preventative effect on SSI $(\mathrm{B}, 2 \mathrm{a})$.

\section{Rationale}

Ten RCTs that analyzed the presence or absence of MBP in colorectal surgery and the incidence of SSI ${ }^{(81-90)}$ found no difference between the RR of 1.02 (95\% CI 0.82-1.28). In a comparison between OAMBP and MBP in colorectal surgery, there was a RR of 0.61 (95\% CI 0.46-0.82) based on the analysis of the $10 \mathrm{RCTs}^{(901-100)}$; OAMBP was found to reduce the rate of SSI significantly. Two large multiplecase studies compared OAMBP and no MBP in colorectal surgery. ${ }^{(101,102)}$ The OR was 0.42 (95\% CI 0.35-0.50), which was significant, and SSI reduction effect was also significantly higher for patients who received OAMBP.

CQ3-10: Does cleansing with chlorhexidine
gluconate prevent SSI?
Recommendations
Preoperative cleansing of the skin with chlorhexidine
gluconate has no effect on preventing SSI $(\mathrm{B}, 4)$.

\section{Rationale}

The meta-analysis ${ }^{(103-112)}$ showed that cleansing the skin with chlorhexidine did not reduce the occurrence of SSI (RR 0.94 ; $95 \%$ CI $0.85-1.05$ ). 


\section{CQ3-11: Is clipper hair removal better for SSI} prevention than shaving?

\section{Recommendations}

Shaving to reduce the rate of SSI has been recommended by some and not by others (A, 5). There is no difference in the incidence of SSI after clipper hair removal, no hair removal, or using hair depilation cream (B).

\section{Rationale}

In a meta-analysis comparing clipper hair removal, depilation and shaving ${ }^{(113-119)}$, the RR of 0.54 (95\% CI 0.38-0.78) was significant and the incidence of SSI was significantly lower after clipper hair removal. In the comparison of depilatory cream and shaving, the SSI was lower after the depilatory cream, not significantly ${ }^{(120-124)}$ (RR 0.52; 95\% CI $0.24-1.11)$. In the comparison between no hair removal and shaving $^{(113,121,125-128)}$, the RR was 0.58 (95\% CI 0.34-0.98), which was significant, and the incidence of SSI was low in the absence of hair removal.

\section{Prophylactic antibiotics}

CQ4-1. What surgical procedures are indicated
for prophylactic antibiotics?
Recommendations
Treatment with prophylactic antibiotics is considered
beneficial in gastrointestinal surgery for its
promising effectiveness in preventing SSIs in both
laparoscopic cholecystectomy (A, 2a) and inguinal
hernia surgery $(\mathrm{B}, 2 \mathrm{a})$.

\section{Rationale}

Figure 4-1 shows the results of a meta-analysis of 13 RCTs evaluating prophylactic antibiotic treatment for laparoscopic cholecystectomy $^{(129-141)}$. Prophylactic antibiotic treatment resulted in a significant reduction in SSI incidence, and given that population sizes were sufficiently large, at 2000 patients in each RCT, the information was given a level of evidence of A. Similarly, Fig. 4-2 shows the results of a meta-analysis of the effects of prophylactic antibiotic treatment for inguinal hernia surgery. The results of these analyses demonstrate that prophylactic antibiotic treatment is effective, even for laparoscopic cholecystectomy and radical inguinal hernia surgery, both of which involve a low degree of surgical site contamination. Therefore, one can infer that prophylactic antibiotic treatment is effective in the field of gastrointestinal surgery with a higher degree of contamination and incidence of SSIs. Hence, prophylactic antibiotic treatment is deemed beneficial in gastrointestinal surgery.

CQ4-2. What is the appropriate timing of prophylactic antibiotic treatment?

\section{Recommendations}

Although evidence is limited, administration within 60 minutes before the surgical incision is preferred (D, 2b).

\section{Rationale}

Three cohort studies compared SSI incidence after administration within $1 \mathrm{~h}$ before the surgical incision versus more than $1 \mathrm{~h}$ before the surgical incision ${ }^{(142-144)}$. Overall, 3606 patients received prophylactic antibiotic treatment within $1 \mathrm{~h}$ before the surgical incision and 3386 received prophylactic antibiotic treatment more than $1 \mathrm{~h}$ before the surgical incision. Analysis revealed an OR of 0.91 (95\% CI 0.71-1.15) and no significant difference between the groups. However, theoretically, attaining an appropriate blood concentration of prophylactic antibiotics by the time of surgical incision is preferred, and hence the conventional administration method is recommended.

\section{CQ4-3. When should prophylactic antibiotics be} re-administered during surgery?

\section{Recommendations}

No high-quality studies have shown that the intraoperative re-administration of prophylactic antibiotics reduces the SSI incidence, the utility of readministration is not known, and there is no basis for recommending when re-administration is appropriate (C). 


\section{Rationale}

Although no high-quality study has shown that the SSI incidence is reduced by intraoperative re-administration of prophylactic antibiotics, from the viewpoint of $\mathrm{PK}$ and $\mathrm{PD}$, it is logical that an appropriate blood concentration of antibiotics should be maintained during surgery, so intraoperative re-administration is preferred. Nevertheless, the appropriate timing of re-administration and how to adjust timing when severe bleeding occurs have not been established.

CQ4-4: What is the optimal duration of
prophylactic antibiotic treatment?
Recommendations
Among patients undergoing elective gastrectomy for
gastric cancer, there was no increase in SSI incidence
in those who were administered prophylactic
antibiotics only before surgery, compared with those
who also received prophylactic antibiotics after
surgery. For this reason, only administration before
surgery (including additional intraoperative
treatment when surgery exceeds 3 hours) is
recommended (B, 2a).
Evidence on the duration of prophylactic antibiotic
treatment for elective colectomy for colorectal cancer
is limited, and at this point, the difference in the
benefit of administration only before surgery versus
both before and after surgery is unknown (C, 3).

\section{Rationale}

Figures 4-3 and 4-4 show forest plots of the SSI incidence after single dosing and repeated dosing of prophylactic antibiotics for gastrectomy and colectomy. Overall, the analysis for gastrectomy revealed a risk ratio (RR) of 0.97 (95\% CI 0.55-1.68) and showed that SSI incidence was not increased significantly, even in the preoperative/intraoperative treatment group ${ }^{(144-147)}$. However, since the population size was not sufficiently large, this was given a level of evidence of B. Similarly, even in cases of elective colectomy for colorectal cancer, the SSI incidence did not increase significantly with single-dose treatment versus repeateddose treatment. However, because there were only two
RCT reports, the population size was small, and because the control group and intervention group differed greatly between the reports, the information was given a level of evidence of $\mathbf{C}$.

\section{Intraoperative management}

CQ 5-1: Which of the following is more useful for
SSI prevention: surgical hand scrubbing or
rubbing?
Recommendation
Surgical hand scrubbing and rubbing exhibit
equivalent effects in SSI prevention. Either method
is acceptable but should be performed appropriately
(A, No recommendation).

\section{Remarks}

A similar description was found in some American ${ }^{(148)}$ and European $^{(149,150)}$ guidelines and no significant difference was found. There were three interventional RCTs with SSI incidence as the outcome, with the same conclusion ${ }^{(151-153)}$. Three observational studies with SSI incidence as outcome and three RCTs with a colony-forming unit (CFU) as an outcome were also confirmed ${ }^{(151,154-158)}$. The superiority of either hygiene method has not been confirmed in any meta-analysis.

\section{Rationale}

Rubbing with alcohol-based hand antiseptic is often performed instead of the conventional hand washing (scrubbing) with running water and soap for surgical hand hygiene. These methods have been compared in some guidelines $^{(148-150)}$, but it has not been confirmed which method is superior. Intervention studies targeting SSI incidence as an outcome have not shown any superiority of either method. Moreover, observational studies using SSI incidence and RCTs with CFU as an outcome have not confirmed the superiority of either method.

A study from Japan identified some reports that the cost of the rubbing method is cheaper than the scrub method ${ }^{(159)}$, but the number of cases was low and the evidence level is low. 


\section{CQ 5-2: Which antiseptics recommended for} surgical site skin preparation prevent SSI most effectively?

\section{Recommendations}

The panel recommends alcohol-based antiseptic solutions with chlorhexidine gluconate for surgical site skin preparation for patients undergoing gastrointestinal surgical procedures $(\mathrm{B}, 2 \mathrm{a})$.

\section{Rationale}

The most widely used agents for surgical skin preparation were povidone iodine or alcohol-based chlorhexidine gluconate solutions. The World Health Organization's (WHO) 2016 Guidelines for the Prevention of Surgical Site Infections include recommendations for surgical site skin preparation $^{(150)}$. Alcohol-based antiseptic solutions based on chlorhexidine gluconate for surgical site skin preparation were recommended. It is important to identify which skin antiseptics for surgical site skin preparation are most effective for preventing SSI.

The meta-analysis was conducted with three RCTs $^{(160-162)}$. These three trials compared the efficacy of aqueous-based povidone iodine with alcohol-based chlorhexidine gluconate solutions for preventing SSI. The metaanalysis indicated that alcohol-based antiseptic solutions based on chlorhexidine gluconate are more effective than aqueous-based povidone iodine in reducing the risk of SSI in patients undergoing gastrointestinal surgery (Fig. 5-1). However, several factors require attention when applying this recommendation in clinical practice. The concentration of antiseptic agent varied among the studies, with the iodophor compound ranging from 5-10\% and chlorhexidine gluconate ranging from $0.5-2.5 \%$. Furthermore, we cannot use chlorhexidine gluconate solutions with a concentration over $1 \%$ in Japan. In future studies, we need to examine the appropriate concentration of chlorhexidine gluconate solutions for clinical practice in Japan. There are eight reports of a fire in the operating room associated with the use of alcohol-based antiseptics solutions in Japan. Measures should be taken to prevent such incidents before the use of alcohol-based antiseptic solution for surgical site skin preparation. We also need to check if patients have allergies to components of the antiseptics. Aqueous-based chlorhexidine gluconate should be used when a patient has alcohol intolerance.
Olanexidine has been introduced for surgical site skin preparation. Olanexidine has antimicrobial activity against a wide range of Gram-positive and Gram-negative bacteria. It also has bactericidal activity against Vancomycinresistant enterococci, Pseudomonas aeruginosa, Serratia spp., and Cepacia spp. A clinical trial to elucidate whether these various concentrations antiseptics and Olanexidine are more effective than alcohol-based antiseptics should be performed.

CQ 5-3: Is the use of adhesive drapes effective for preventing SSI?

Recommendations

The effectiveness of adhesive drapes for preventing $\mathrm{SSI}$ is unclear $(\mathrm{C}, 3)$.

\section{Rationale}

SSIs often develop after gastrointestinal surgical procedures; these wounds are mostly classified as clean-contaminated wounds. Various strategies, such as single-use drapes, are used to reduce wound contamination during a surgical procedure; however, their effectiveness in preventing wound infection is limited. For this reason, adhesive drapes are now used widely to reduce wound contamination.

We identified three RCTs ${ }^{(164-166)}$ and one observational study ${ }^{(167)}$. The observational study found that SSI was significantly less likely when surgery was performed with adhesive drapes. The meta-analysis was conducted with three $\mathrm{RCTs}^{(164-166)}$. Results from the meta-analysis indicated that surgery with adhesive drapes did not reduce the risk of SSI compared with surgery without adhesive drape (Fig. 5-2).

CQ 5-4: Can using wound protector devices effectively prevent SSI?

\section{Recommendations}

The use of wound protector devices, especially a double-ring wound protector device used in gastrointestinal surgical procedures, reduces the rate of $\operatorname{SSI}(\mathrm{A}, 2 \mathrm{a})$. 


\section{Rationale}

Despite using various strategies to minimize surgical wound contamination during surgery, incisional SSIs often occur after gastrointestinal surgical procedures. These wounds are usually classified as clean-contaminated wounds. Currently, surgical wound protectors, which comprise a non-adhesive plastic sheath attached to a single or double rubber ring that secures the sheath to the wound edges, are available to reduce wound edge contamination.

A meta-analysis was conducted with eight $\mathrm{RCTs}^{(168-175)}$ comparing the use of a surgical wound protector with conventional wound protection for preventing SSI. The metaanalysis indicated that wound protector devices are significantly more effective than conventional wound protection for reducing the risk of SSI in patients undergoing gastrointestinal surgery (Fig. 5-3). One trial performed an economic evaluation of wound protector devices ${ }^{(176)}$ and found no evidence to suggest that wound-edge protection devices are a cost-effective device to reduce SSI. There were several limitations in this analysis. First, the structural design of wound protector devices varied among the studies. Second, this analysis was unable to evaluate the efficacy in preventing SSI between the single-ring and the double-ring wound protector devices. Third, all studies targeted open gastrointestinal surgery. It is unknown whether the use of wound protector devices in laparoscopic surgeries can reduce the risk of SSI.

\section{CQ 5-5: Are double-gloving, glove changing, or} repeated hand washing during surgery effective for preventing SSI?

\section{Recommendations}

We suggest the use of double-gloving during surgery due to safety concerns since glove perforation may cause occupational exposures, injuries, or infections (A, 2b).

\section{Remarks}

We cannot provide any recommendations for the use of double-gloving (D), changing gloves (C), or repeated hand washing (D) during digestive surgery for preventing SSI due to the lack of supporting evidence (D). However, doublegloving can reduce the exposure risk since the incidence of glove perforation is significantly lower for the inner gloves (A).

\section{Rationale}

The WHO stated that a recommendation could not be formulated because of the lack of evidence ${ }^{(150)}$. However, it stated that most surgeons prefer to double-glove because bacterial contamination of the surgical field may occur in the event of glove perforation and most surgeons prefer to wear double gloves for their own protection against injury or infections.

There were no RCTs or observational studies concerning double-gloving for digestive surgery and the incidence of SSI. On the other hand, five RCTs were identified concerning glove perforations ${ }^{(177-181)}$. In the meta-analysis of these five RCTs, the incidence of perforation in single-gloving was significantly higher than that in the inner gloves used in double-gloving (Fig. 5-5). We could not find any RCTs in digestive surgery concerning changing gloves during surgery. Although we found an observational study with low quality evidence for changing gloves, there were no significant effects ${ }^{(182)}$. Moreover, we could not find any RCTs or OBSs in digestive surgery concerning repeated hand washing for preventing SSI. Thus, we could not formulate any recommendations for using double-gloving, changing gloves, or repeated hand washing during digestive surgery to prevent SSI. However, the incidence of glove perforation was significantly lower with double-gloving than with single-gloving.

The limitations of this analysis were as follows: (1) There was no cost analysis. (2) There was no evidence for whether glove perforation can actually lead to occupational infections. (3) Using double-gloving may reduce operability, although no evidence could be provided.

\section{CQ 5-6: Can changing instruments during} surgery effectively prevent SSI?

\section{Recommendations}

The efficacy of changing instruments during surgery to prevent SSI is unclear due to the lack of evidence; hence, we do not actively recommend this practice. However, the practice of changing instruments is recommended to avoid potentially dirty or contaminated surgical operations (D, 2b).

\section{Rationale}

We could not address this CQ fully as there are no RCTs on the correlation between changing instruments and preventing SSI. Further studies are needed. 


\section{CQ 5-7: Are antimicrobial-coated sutures} effective for preventing SSI?

\section{Recommendations}

We recommend the use of antimicrobial-coated sutures for preventing SSI during digestive surgery (B, 2a).

\section{Rationale}

A total of $10 \mathrm{RCTs}$ and 5 observational studies were identified $^{(183-197)}$. We analyzed the incidence of SSI and the duration of hospitalization.

The results of a meta-analysis of all 10 RCTs showed that antimicrobial-coated sutures used in digestive surgery were effective for preventing SSI (RR 0.68; 95\% CI 0.48-0.95; $\mathrm{p}=0.03$ ) (Fig. 5-5). However, in the analyses distinct from suture material, we could find significant efficacy only for poly-filament suture (RR 0.45; 95\% CI 0.26-0.77; $\mathrm{p}=0.004$ ) in six RCTs, but not even for these in four RCTs (RR 0.79; 95\% CI 0.54-1.17; $\mathrm{p}=0.24)$. Analysis of five RCTs showed that the duration of hospitalization did not decrease significantly when antimicrobial-coated sutures were used (risk differences [RD] - 0.5; 95\% CI - 16.68-6.69; $\mathrm{p}=0.40$ ). Thus, we recommend the use of antimicrobial-coated sutures to prevent SSI in digestive surgery. However, studies on cost benefit, efficacy in a pediatric population, or adverse events are lacking. All analyzed results of this systematic review can be found in the report by Uchino et al. ${ }^{(198)}$.

CQ 5-8: Is wound irrigation before closure useful
for preventing SSI?
Recommendations
We recommend wound irrigation, especially with
high pressure, for preventing SSI (C, 2a). However,
we cannot provide a recommendation for wound
irrigation with disinfectant, antibiotics, or
electrolyzed acidic aqueous solution due to the lack
of evidence (D, 3).

\section{Rationale}

We could find only one RCT published since 2000, that examines the efficacy of wound irrigation in appendectomies ${ }^{(199)}$. In a systematic review and meta-analysis reported in 2015, wound irrigation was found to be significantly more effective in preventing $\mathrm{SSI}^{(200)}$. However, this meta-analysis included 15 appendectomies among 34 RCTs and 33 of the 34 studies were conducted before 2000. It is difficult to apply these results to recent cases of abdominal surgery, or even laparoscopic surgery. Therefore, recent evidence is insufficient on the relationship between wound irrigation and SSI.

We found two RCTs on high-pressure wound irrigation $^{(199,201)}$ in appendectomy and hepatic surgery, and three observational studies ${ }^{(202-204)}$. Although a significant effect was found in the meta-analysis for RCTs (Fig. 5-6) and OBSs (Fig. 5-7), evidence levels were low in both RCTs due to unclear definitions of outcome, randomization, concealment, and assessment of outcomes. Moreover, several methods of high-pressure irrigation were used in these studies, including pulsation and syringe with or without a thin needle.

Wound irrigation with disinfectant or antibiotic solution has not been practiced in digestive surgery since 2000 .

There were two RCTs concerning the use of wound irrigation with electrolyzed acidic aqueous solution in preventing $\mathrm{SSI}^{(205,206)}$; however, no significant efficacy was observed for preventing SSI (RR 0.42; 95\% CI 0.09-2.03; $\mathrm{p}=0.19$ ). Conversely, using electrolyzed acidic aqueous solution could be harmful since wound dehiscence and herniation were increased in one RCT (RR 2.28; 95\% CI 1.03-5.04; $\mathrm{p}=0.04)^{(8)}$. Based on these results, we recommend wound irrigation, especially with high pressure, for preventing SSI. However, a recommendation for wound irrigation with disinfectant, antibiotics, or electrolyzed acidic aqueous solution could not be formulated due to the lack of evidence in digestive surgery.

\section{CQ 5-9: Is peritoneal lavage before closure} effective for preventing SSI?

\section{Recommendations}

We do not recommend peritoneal lavage for preventing SSI due to lack of evidence (D, 3). 


\section{Rationale}

Figures 5-8 and 5-9 show the results of a meta-analysis of three RCTs $^{(207-209)}$ and two observational studies ${ }^{(210,211)}$, respectively. Peritoneal lavage appeared to be harmful in one RCT on elective hepatic surgery, although there was no significant difference (RR 2.31; 95\% CI 0.99-5.36) ${ }^{(1)}$. The other two RCTs were conducted on restricted to open appendectomy ${ }^{(208,209)}$. Two observational studies were also conducted on restricted to open appendectomy ${ }^{(210,211)}$. Although the RCTs did not find significant efficacy, analysis of the observational studies found that it was significantly harmful. However, we could not apply these results to universal digestive surgery for either emergency surgery with dirty/infected wounds or elective surgery with clean-contaminated wounds. Therefore, we cannot comment on the efficacy of peritoneal lavage for preventing SSI due to the lack of evidence.

\section{CQ-5-10: Does drain placement after digestive} surgery reduce the incidence of SSI?

\section{Remarks}

The 2016 WHO Guidelines for the Prevention of SSI include recommendations for the optimal timing of removing drains ${ }^{150)}$. The recommendations state that there is no high-quality evidence on the optimal timing of draining for SSI prevention and drains should be removed based on clinical judgment. Therefore, the evidence level is low and is considered a conditional recommendation. For this guideline, we addressed the CQ regarding which drain placement after each gastroenterological surgery could have an impact on SSI.

*The final decision on drain placement or nonplacement is based on the consideration of individual risk factors, the clinical outcome of the facility, and the skill of the operator. This recommendation could reflect advanced medical levels above the national average and encompass non-standard possibilities. Therefore, even with CQs that are recommended not to be detained, it might be outside the standard medical level in a non-specialized hospital.
CQ 5-10-1: Is drain placement after gastric cancer necessary for SSI prevention?

\section{Recommendations}

Drain placement after surgery for gastric cancer does not prevent SSI. Drain placement is not necessary because mortality and complication rates are also low $(\mathrm{B}, 3)$.

\section{Rationale}

The reported RCTs ${ }^{(212-214)}$ were considered with few observational studies and high evidence. Two observational studies were also considered $^{(215,216)}$. There was no significant difference in mortality rates after total gastrectomy and distal gastrectomy with versus without drain placement (Figs. 5-10 and 5-11, respectively). We recommend that drain placement after gastrectomy be judged according to the clinical outcome and skills of the individual institution (B, 3).

\begin{tabular}{l} 
CQ 5-10-2: Does drain placement after \\
laparoscopic cholecystectomy reduce the \\
incidence of SSI? \\
Recommendations \\
Complications, SSI incidence, and mortality are \\
similar with or without draining after laparoscopic \\
cholecystectomy and the operation time was shorter \\
without drainage. Therefore, drain placement is not \\
required (A, 4). \\
\hline
\end{tabular}

\section{Rationale}

Results from a meta-analysis of 13 RCTs had a high evidence level because of the homogenous population and the inclusion of more than 500 cases $^{(217-229)}$. There is no disadvantage for patients without drain placement because the mortality rate was not different with or without a drain. Moreover, the SSI rate did not differ among the groups, although that in the no-drain group tended to be lower than that in the drain group (Fig. 5-12). On the other hand, most investigators recommend no drain after laparoscopic cholecystectomy because of some benefits, such as shortening the operation time (Fig. 5-13). Therefore, committee members 
recommend that drainage after laparoscopic cholecystectomy is unnecessary (A, 4).

CQ 5-10-3: Is draining necessary after
hepatectomy without biliary reconstruction?
Recommendations
No drainage after hepatectomy without biliary
reconstruction tends to have a lower SSI rate, less
ascites, and shorter hospitalization. Therefore, the
committee recommends that drain placement after
hepatectomy is unnecessary. $(\mathrm{A}, 4)$

\section{Rationale}

The meta-analysis was conducted with six RCTs ${ }^{(230-235)}$. Mortality rates were not significantly different between the drain and no-drain groups (Fig. 5-14). The SSI rates tended to be higher in the drain group (Fig. 5-15) and ascitic fluid leakage was significantly reduced in the no-drain group (Fig. 5-16). Therefore, as drain placement after hepatectomy without biliary reconstruction tends to increase SSI rates, ascitic leakage, extend the duration of hospitalization, no drain is recommended with high evidence levels (A, 4).

CQ 5-10-4: Does intraperitoneal drain placement after pancreatoduodenectomy reduce the occurrence of SSI? Could early removal of the drain prevent SSI?

\section{Recommendations}

SSI tends to be higher without drainage and some studies have been discontinued due to increased mortality rates. Thus, it is recommended to use a drain (B, 2b). Regarding the duration of drain placement, the committee recommends that it be removed early according to the criteria for postoperative pancreatic juice, and that the patients should be selected carefully.

\section{Rationale}

The meta-analysis was conducted with three RCTs ${ }^{(236-238)}$. The Van Buren's (2014) RCT study ${ }^{(237)}$ for a pancreatoduodenectomy was discontinued by the study's Medical Safety Commission (Fig. 5-17) ${ }^{(239)}$. Therefore, it is suggested that no drainage may increase the mortality rate, and drain placement is better from the viewpoint of medical safety $(\mathrm{B}, 2 \mathrm{~b})$. Concerning the timing of drain removal, the group that had early drain removal after surgery within certain removal criteria had fewer intraabdominal infections (Fig. 5-18), and the duration of hospitalization was also shortened significantly (Fig. 5-19). Early removal is recommended by the committee, although this does not have a high evidence level and the number of cases is limited.

CQ 5-10-5: Does intraperitoneal drain placement after appendectomy prevent SSI?

\section{Recommendations}

No drain after appendectomy is better for preventing SSI. Drain placement may increase the incidence of complications and mortality. Therefore, we do not recommend drain placement after appendectomy. (B, 4)

\section{Rationale}

It is important to note that all evidence was collected for open surgery using a Penrose drain. Although the evidence level was moderate, most appendectomies are now performed under laparoscopy and the clinical background of the studies and medical reality differs. With this limited evidence, a meta-analysis was conducted with seven $\mathrm{RCTs}^{(239-245)}$. Mortality rates (Fig. 5-20) were lower in the no-drain group. Therefore, drain placement after appendectomy is unnecessary, unless patients need abdominal lavage. 
CQ 5-10-6: Does intraperitoneal drain placement for intra- or extra- abdominal anastomosis after colorectal surgery prevent SSI?

\section{Recommendations}

Drain placement is unnecessary to prevent SSI after colon surgery $(A, 4)$. The clinical benefit of drain placement is unclear, and it might be unnecessary. On the other hand, drain placement could be considered in specific cases when it might contribute to reducing severe complications $(\mathrm{A}, 3)$.

\section{Rationale}

Drain placement does not affect the clinical outcome of suture failure, abscess formation, or mortality, after colon surgery or rectal surgery. Although there was no significant difference in rectal surgery, the incidence of mortality (Fig. 5-21) tended to be lower in the drain group ${ }^{(246-249)}$. In colon surgery, we did not identify any merits of drain placement or of no drain placement ${ }^{(250-253)}$. The committee recommend that drain placement is unnecessary (Recommendation 4). There was no significant difference in rectal surgery, and the merits of drain placement are unclear, although drain placement tends to reduce serious complications (Recommendation 3).

CQ 5-10-7: Does subcutaneous drain placement after abdominal surgery prevent SSI?

\section{Recommendations}

Although subcutaneous drain placement may reduce the incidence of SSI, it is necessary to consider the indications for appropriate cases, methods, and duration. $(\mathrm{B}, 3)$

\section{Rationale}

The meta-analysis was conducted with seven RCTs ${ }^{(254-260)}$, which showed that the incidence of superficial incision wounds in SSI was significantly reduced when subcutaneous drains were placed (Fig. 5-22). With respect to the high evidence level of the studies included in the meta-analysis, subcutaneous draining appears to reduce the incidence of SSI after gastrointestinal tract surgery (Evidence level, B). However, there is no clear recommendation because the subcutaneous drains in clinical practice are not widespread, and the indication in clinical practice is inconclusive.

CQ 5-11: Could methods for closing the wound,
the type of sutures, and bio-adhesives have an
impact on the SSI?
Remarks
Wound closure methods that contain antibiotics are
recommended by several guidelines to prevent
superficial SSI. However, study comparisons show
remarkable differences such as in suture materials
and suturing methods. Therefore, the committee have
adapted direct comparisons regarding the prevention
of superficial SSI.

CQ5-11-1: Do absorbable sutures reduce the incidence of SSI in primary would closure compared with non-absorbable sutures in subcutaneous suturing?

Recommendations

Subcutaneous suturing using absorbable materials is recommended. $(\mathrm{B}, 3)$

\section{Rationale}

Meta-analysis of six RCTs for superficial SSI ${ }^{(261-266)}$ revealed a significantly lower incidence of SSI when absorbable sutures were used than when non-absorbable sutures were used (Fig. 5-23). The meta-analysis from appendectomy alone showed that the incidence of superficial SSI was significantly lower for absorbable sutures than non-absorbable sutures. Therefore, absorbable sutures are more clinically valuable than non-absorbable sutures for superficial SSI and wound dehiscence in primary closure using subcutaneous sutures ${ }^{(261-266)}$. 


\section{CQ 5-11-2: Is there any difference in the incidence of SSI between continuous sutures and interrupted sutures for primary wound closure after gastroenterological surgery? \\ Recommendations \\ Continuous sutures tended to result in less wound dehiscence and fewer wound infections than interrupted sutures for subcutaneous suturing after gastroenterological surgery. Therefore, we recommend continuous sutures over interrupted sutures for subcutaneous suturing $(\mathrm{B}, 2 \mathrm{a})$. In fascia closure, the incidences of SSI and wound hernia were not different between continuous sutures and interrupted sutures, so either method can be used (B, $3)$.}

\section{Rationale}

A meta-analysis of four RCTs for superficial SSI and wound dehiscence for subcutaneous suturing ${ }^{(262,263,267,268)}$ revealed that the incidence of wound dehiscence was significantly lower for continuous sutures than for interrupted sutures (Fig. 5-24). A meta-analysis of eight RCTs for superficial SSI and hernia formation for fascia closure ${ }^{(269-276)}$ revealed that the SSI rate and hernia formation were not different between continuous and interrupted sutures. Because there was less wound dehiscence associated with continuous sutures, interrupted sutures are strongly recommended for subcutaneous suturing.

\section{CQ 5-11-3: Does subcutaneous suturing using} absorbable materials reduce the incidence of SSI more effectively than skin closure using a stapler?

\section{Recommendations}

Subcutaneous suturing using absorbable materials does not reduce the incidence of SSI compared with skin closure using a stapler. However, it is recommended for cosmetic purposes and patient satisfaction $(B, 2 b)$.

\section{Rationale}

A meta-analysis of two RCTs on the rate of SSI rate and wound complications after skin closure using subcutaneous sutures versus a skin stapler ${ }^{(277,278)}$ revealed that the incidence of each clinical indicator for subcutaneous sutures tended to be less than that for skin stapling. The RCTs consisted of more than 1000 subjects and had high statistical power. Subcutaneous sutures resulted in less wound thickness than a skin stapler. Patient satisfaction after subcutaneous sutures were used ranked excellent and obtained $54 \%$ (268/511), whereas patient satisfaction after a skin stapler was used obtained only $42.7 \%$ (211/494: $\mathrm{P}=0.002)$.

CQ5-11-4: Do bioadhesives reduce the incidence
of SSI for primary would closure in laparoscopic
surgery compared with sutures alone?
Recommendations
The rates of SSI and wound dehiscence when
bioadhesives were used for primary wound closure
was comparable to that of sutures alone.
Bioadhesives may improve cosmetic results and
shorten operation time in primary wound closure
after laparoscopic surgery (C, 3 ).

\section{Rationale}

The number of patients in each study was small, so the evidence level was C. A meta-analysis of six RCTs that compared bioadhesives and subcutaneous sutures ${ }^{(279-284)}$ revealed that the incidence of SSI and wound dehiscence was similar for both methods. The cost of using bioadhesives could be higher than that of subcutaneous sutures and it can also cause chemical burns. Therefore, the clinical application of these materials must be carried out carefully. 


\section{Perioperative management}

\section{CQ-6-1: Does an early recovery program (ERP)} after digestive surgery reduce the incidence of SSI?

\section{Recommendations}

Implementation of an ERP is recommended to reduce the incidence of SSI in patients undergoing digestive surgery, and to shorten the length of hospital stay and acceleratevrecovery of gut function (A, 2a). However, it remains unclear which components of the program are optimal for SSI prevention after the various types of digestive surgery.

\section{Rationale}

Figure 6-1 shows the results of a meta-analysis of 29 $\mathrm{RCTs}^{(285-313)}$ on early recovery after surgery (ERAS)/Fast Track Surgery (FTS) for digestive surgery. Implementation of an ERP like ERAS/FTS significantly reduced the incidence of SSI after digestive surgery. The length of hospital stay (standardized mean difference [SMD]: -1.05 day; $95 \%$ CI $-1.41,-0.75$ ) and overall postoperative complications (RR $0.76 ; 95 \%$ CI $0.63,0.93$ ) were significantly lower in the ERAS/FTS groups. Another meta-analysis of 27 RCTs also demonstrated that ERAS/FTS for abdominal or pelvic surgery had a similar effect on SSI prevention (RR 0.77; 95\% CI 0.58, 0.98) ${ }^{(314)}[30]$. Therefore, we recommend ERP after digestive surgery to decrease the risk of SSI (A, 2a). However, it remains unclear which program components are optimal to prevent SSI after various types of digestive surgery because several components constituting ERP were different in every type of digestive surgery reported.

\section{CQ-6-2: Is preoperative carbohydrate (CHO)}

loading effective for preventing SSI?

\section{Recommendations}

Preoperative $\mathrm{CHO}$ loading does not prevent SSI after digestive surgery. Therefore, the implementation of preoperative $\mathrm{CHO}$ loading is not recommended for SSI prevention. (A, 3).

\section{Rationale}

Meta-analysis of six $\mathrm{RCTs}^{(315-320)}$ on preoperative $\mathrm{CHO}$ loading did not show any effect on SSI prevention after digestive surgery (Fig. 6-2). Another meta-analysis of 8 RCTs ahowed no significant difference in the incidence of postoperative complications (RR 0.85 ; 95\% CI $0.66,1.08$ ) between preoperative $\mathrm{CHO}$ loading and a placebo ${ }^{(315-322)}$. A meta-analysis of preoperative $\mathrm{CHO}$ loading for elective surgery, including cardiovascular and hip joint surgery, also showed no effect on preventing surgical complications (RR $0.88 ; 95 \%$ CI $0.50,1.55)^{(323)}$. Therefore, we do not recommend the preoperative administration of $\mathrm{CHO}$ to prevent SSI (A, 3).

CQ-6-3: What is the target perioperative blood glucose level for SSI prevention?

\section{Recommendations}

A blood glucose level of less than $150 \mathrm{mg} / \mathrm{dL}$ is desirable because strict blood glucose control during the postoperative period reduces the incidence of SSI significantly in digestive surgery patients with and those without diabetes mellitus $(\mathrm{B}, 2 \mathrm{~b})$. On the other hand, blood glucose should be closely monitored due to the inherent risk of a hypoglycemic event.

\section{Rationale}

The American College of Surgeons (ACS)/Surgical Infection Society (SIS) guideline recommends a target blood glucose level to prevent SSI of $110-150 \mathrm{mg} / \mathrm{dL}$, and less than $180 \mathrm{mg} / \mathrm{dL}$ for cardiovascular surgery ${ }^{(324)}$. The CDC guideline recommends a target blood glucose level of less than $200 \mathrm{mg} / \mathrm{dL}^{(325)}$ and the WHO global guideline suggests $110-150 \mathrm{mg} / \mathrm{dL}$ or less than $150 \mathrm{mg} / \mathrm{dL}$ without a definitive recommendation ${ }^{(150)}$. To address the optimal blood glucose target level for SSI prevention in digestive surgery, four $\operatorname{RCTs}^{(326-329)}$ and three observational studies ${ }^{(330-332)}$ were identified. In a meta-analysis of the four RCTs, the summary estimate showed a significant benefit of intensive glucose control compared with conventional control for reducing the incidence of SSI in patients with and those without diabetes (Fig. 6-3). The intensive group's target blood glucose levels were $80-110 \mathrm{mg} / \mathrm{dL}$ in the four RCTs, resulting in a high incidence of hypoglycemic events (RR 7.11, 95\% CI 2.15, 23.55). The target levels of blood glucose were different in each observational study: $80-140 \mathrm{mg} / \mathrm{dL}$, less than $125 \mathrm{mg} /$ 
$\mathrm{dL}$, and less than $180 \mathrm{mg} / \mathrm{dL}$, respectively. The incidences of SSI in each glucose control group were significantly lower than those in the reference groups. A recent meta-analysis reported that the effect was similar in studies with a target blood glucose level of less than $110 \mathrm{mg} / \mathrm{dL}$ (RR 0.50; 95\% CI $0.35,0.73$ ) and an upper limit target level of $110-150 \mathrm{mg} /$ $\mathrm{dL}$ (RR 0.43; 95\% CI 0.29, 0.63) ${ }^{(333)}$. Considering this evidence, we recommend blood glucose target levels of less than $150 \mathrm{mg} / \mathrm{dL}$ to reduce the incidence of SSIs in digestive surgery patients with and those without diabetes mellitus; however, the available evidence is low quality and hypoglycemic events should be avoided in intensive glucose control (B, 2b).

CQ-6-4: Is perioperative oral hygiene helpful
for preventing SSI after digestive surgery?
Recommendations
There are no guidelines on whether perioperative oral
hygiene is helpful for preventing SSI in
gastrointestinal surgery because of the lack of
evidence (D). On the other hand, perioperative oral
hygiene may help to prevent postoperative
pneumonia after esophagectomy.

\section{Rationale}

We did not identify any RCTs or observational studies investigating the relationship between oral hygiene and the incidence of SSI in digestive surgery in English language journals. Only one observational study found that preoperative dental care significantly reduced severe pneumonia after esophagectomy (Fig. 6-4) ${ }^{(334)}$. The evidence level of this retrospective study was low. However, preoperative oral care appears to have become adopted widely in the field of cancer surgery. We decided not to provide a recommendation about preoperative oral care and SSI prevention.

CQ 6-5: Does maintaining normothermia during
surgery reduce SSI?
Recommendations
Intraoperative warming for maintaining
normothermia is recommended to prevent SSI. (B,
2a).

\section{Rationale}

A meta-analysis was conducted with two $\operatorname{RCTs}^{(335,336)}$ (Fig. 6-5). Intraoperative warming and maintaining normothermia significantly reduces the risk of SSI after surgery compared with non-warming care. However, the evidence level is moderate (B) because the two RCTs contained small sample sizes and there have been no recent large-scale studies on digestive surgery. Intraoperative hypothermia causes not only SSI but also postoperative shivering, delayed emergence from anesthesia, and abnormal coagulation. Thus, patients should be warmed and normothermia with a core temperature $>36{ }^{\circ} \mathrm{C}$ maintained during surgery using methods such as forced-air warming, warming blankets, and a fluid warmer.

\section{CQ 6-6: Is perioperative high $\mathrm{F}_{1} \mathrm{O}_{2}$ beneficial for}

\section{SSI prevention?}

\section{Recommendations}

High oxygen concentrations $\left(\mathrm{F}_{\mathrm{I}} \mathrm{O}_{2}\right.$ of 0.8$)$ during and 2-6 hours after colorectal surgery may reduce the risk of SSI (B, 3). However, high concentrations of oxygen also have adverse effects such as absorption atelectasis and oxygen toxicity. Furthermore, the safety of high oxygen concentrations during long operations is not supported. Thus, the indication for high $\mathrm{F}_{\mathrm{I}} \mathrm{O}_{2}$ must be evaluated carefully.

\section{Rationale}

The meta-analysis was conducted on $10 \mathrm{RCT}$ s on digestive surgery ${ }^{(337-346)}$. High perioperative oxygen concentrations $\left(\mathrm{F}_{\mathrm{I}} \mathrm{O}_{2}\right.$ of 0.8$)$ do not reduce the risk of SSI significantly after digestive surgery, compared with the usual standard of care $\left(\mathrm{F}_{\mathrm{I}} \mathrm{O}_{2}\right.$ of 0.3-0.35) (Fig. 6-6). However, when meta-analysis was conducted on four RCTs on high-concentration oxygen administered during and $2 \mathrm{~h}$ or more after colorectal surgery ${ }^{(337,339,340,346)}$, high $\mathrm{F}_{\mathrm{I}} \mathrm{O}_{2}$ during and 2-6 h after surgery reduced the risk of SSI after colorectal surgery significantly (Fig. 6-7).

The indication for high perioperative $\mathrm{F}_{\mathrm{I}} \mathrm{O}_{2}$ should be evaluated carefully, especially for patients with respiratory diseases such as chronic obstructive pulmonary disease and interstitial pneumonia for whom high oxygen concentrations may exacerbate respiratory failure. In the 10 RCTs on digestive surgery included in this meta-analysis, no harmful injury was reported in the control group, or after the 
administration of high-concentration oxygen for about $3 \mathrm{~h}$ during surgery and up to $6 \mathrm{~h}$ after surgery. On the other hand, the effect of high $\mathrm{F}_{\mathrm{I}} \mathrm{O}_{2}$ during long operations has not been verified, and its safety is unknown. The beneficial effect of perioperative high $\mathrm{F}_{\mathrm{I}} \mathrm{O}_{2}$ on SSI prevention is limited, and its safety is unclear. Therefore, the committee members do not recommend it (recommendation level 3). Further research is needed.

CQ 6-7: Does early postoperative oral and enteral
feeding reduce SSI?
Recommendations
Although early postoperative oral and enteral feeding
does not reduce the risk of SSI (B), it is
recommended for its other benefits such as
shortening the hospital stay.

\section{Rationale}

A meta-analysis was conducted with seven RCTs on digestive surgery (Fig. 6-8) ${ }^{(347-353)}$. Early postoperative oral and enteral feeding does not prevent SSI. The meta-analysis did not show that early postoperative oral and enteral feeding was useful for SSI prevention. However, it is an established element of the ERAS protocol and its usefulness for shortening the length of hospital stay and other advantages is well documented. Therefore, the committee members recommend it.

\section{Wound management}

CQ 7-1: Do wound dressings prevent SSI after abdominal surgery?

\section{Recommendations}

It is recommended to place protective wound dressings over large incisional wounds after abdominal surgery, rather than covering them with gauze (B, 2b).

\section{Rationale}

The results of a meta-analysis of eight RCT reports on the combination of hydrocolloid material and silver-containing wound protection material ${ }^{(355-362)}$ showed that the material for each control varied. Thus, it was considered evidence level B. In the meta-analysis, the use of any protective material reduced the incidence of wound infection significantly (Fig. 7-1). Despite detection bias or technique-related inconsistencies, wound infection is reduced by protective dressings (B, 2b).

CQ 7-2: Is negative-pressure wound therapy (NPWT) in abdominal surgery effective for SSI prevention?

\section{Recommendations}

Although NPWT at primary closure during abdominal surgery may reduce incisional SSI, its indications and cost must be considered $(\mathrm{B}, 3)$.

\section{Rationale}

NPWT for primary incisional wounds had a significantly lower incidence of SSI than gauze dressing from the metaanalysis of four RCTs ${ }^{(363-366)}$ (Fig. 7-2). Seroma formation also tended to be lower with NPWT although the difference was not significant (Fig. 7-3). Thus, NPWT may reduce the incidence of SSI in primary incisional wounds. This recommendation has been made based on consideration that the indication of the disease and the type of surgical procedures varied. The negative pressure and the period were also unstable. Furthermore, Japanese public insurance does not yet cover NPWT for primary incisional wounds.

Open Access This article is licensed under a Creative Commons Attribution 4.0 International License, which permits use, sharing, adaptation, distribution and reproduction in any medium or format, as long as you give appropriate credit to the original author(s) and the source, provide a link to the Creative Commons licence, and indicate if changes were made. The images or other third party material in this article are included in the article's Creative Commons licence, unless indicated otherwise in a credit line to the material. If material is not included in the article's Creative Commons licence and your intended use is not permitted by statutory regulation or exceeds the permitted use, you will need to obtain permission directly from the copyright holder. To view a copy of this licence, visit http://creativecommons.org/licenses/by/4.0/. 


\section{References}

1. Committee for Gastroenterological Surgical Site Infection Guidelines, the Japan Society for Surgical Infection. Japan Society for Surgical Infection: Gastroenterological Surgical Site Infection Guidelines 2018, Shindan To Chiryo sha Inc, Tokyo, 2018 (in Japanese).

2. Guyatt GH, Oxman AD, Kunz R, GRADE Working Group, et al. Incorporating considerations of resources use into grading recommendations. BMJ. 2008a;336:1170-3.

3. Guyatt GH, Oxman AD, Kunz R, GRADE Working Group, et al. Rating quality of evidence and strength of recommendations: going from evidence to recommendations. BMJ. 2008b;336:1049-51.

4. Zhang Y, Coello PA, Guyatt GH, Yepes-Nuñez JJ, Akl EA, Hazlewood G, et al. GRADE guidelines: 20. Assessing the certainty of evidence in the importance of outcomes or values and preferences-inconsistency, imprecision, and other domains. J Clin Epidemiol. 2019;111:83-93.

5. Kalra L, Camacho F, Whitener CJ, Du P, Miller M, Zalonis C, et al. Risk of methicillin-resistant Staphylococcus aureus surgical site infection in patients with nasal MRSA colonization. Am J Infect Control. 2013;41:1253-7 (PMID 23973424).

6. Ramirez MC, Marchessault M, Govednik-Horny C, Jupiter D, Papaconstantinou HT. The impact of MRSA colonization on surgical site infection following major gastrointestinal surgery. J Gastrointest Surg. 2013;17:144-52.

7. Manunga J Jr, Olak J, Rivera C, Martin M. Prevalence of methicillin-resistant Staphylococcus aureus in elective surgical patients at a public teaching hospital: an analysis of 1039 patients. Am Surg. 2012;78:1096-9. (PMID 23025949).

8. Parvez N, Jinadatha C, Fader R, Huber TW, Robertson A, Kjar $\mathrm{D}$, et al. Universal MRSA nasal surveillance: characterization of outcomes at a tertiary care center and implications for infection control. South Med J. 2010;103:1084-91. (PMID 20926991).

9. Gupta K, Strymish J, Abi-Haidar Y, Williams SA, Itani KM. Preoperative nasal methicillin-resistant Staphylococcus aureus status, surgical prophylaxis, and risk-adjusted postoperative outcomes in veterans. Infect Control Hosp Epidemiol. 2011;32:7916. (PMID 21768763).

10. Matsubara Y, Uchiyama H, Higashi T, Edagawa A, Ishii H, Nagata S, et al. Nasal MRSA screening for surgical patients: predictive value for postoperative infections caused by MRSA. Surg Today. 2014;44:1018-25. (PMID 23824338).

11. Perl TM, Cullen JJ, Wenzel RP, Zimmerman MB, Pfaller MA, Sheppard D, et al. Intranasal mupirocin to prevent postoperative Staphylococcus aureus infections. N Engl J Med 2002; 346: 1871-7. PMID 12063371.

12. Bode LG, Kluytmans JA, Wertheim HF, Bogaers D, Vandenbroucke-Grauls CM, Roosendaal R, et al. Preventing surgical-site infections in nasal carriers of Staphylococcus aureus. N Engl J Med. 2010; 362:9-17. (PMID 20054045).

13. Takahashi Y, Takesue Y, Uchino M, Ikeuchi H, Tomita N, Hirano $\mathrm{T}$, et al. Value of pre- and postoperative methicillin-resistant Staphylococcus aureus screening in patients undergoing gastroenterological surgery. J Hosp Infect. 2014; 87:92-7. (PMID 24836292).

14. Suzuki Y, Kamigaki T, Fujino Y, Tominaga M, Ku Y, Kuroda Y. Randomized clinical trial of preoperative intranasal mupirocin to reduce surgical-site infection after digestive surgery. Br J Surg. 2003;90:1072-5. (PMID 12945073).

15. Yano M, Doki Y, Inoue M, Tsujinaka T, Shiozaki H, Monden M. Preoperative intranasal mupirocin ointment significantly reduces postoperative infection with Staphylococcus aureus in patients undergoing upper gastrointestinal surgery. Surg Today. 2000;30:16-21. (PMID 10648077).

16. Sagawa M, Yoshimatsu K, Yokomizo H, Yano Y, Nakayama M, Okayama S, et al. Immuno-nutritional factors affecting the incidence of surgical site infection (SSI) after rectal cancer surgery. Gan To Kagaku Ryoho. 2015;42:1243-5. (PMID 26489560).

17. Fukuda Y, Yamamoto K, Hirao M, Nishikawa K, Maeda S, Haraguchi N, et al. Prevalence of malnutrition among gastric cancer patients undergoing gastrectomy and optimal preoperative nutritional support for preventing surgical site infections. Ann Surg Oncol. 2015;22:S778-85. (PMID 26286199).

18. Igari K, Ochiai T. Risk factors associated with surgical site infection in emergency abdominal surgery of patients over 80 years old (in Japanese with English abstract). Nippon Fukubu Kyukyu (J Abdom Emerg Med). 2012;32:725-30.

19. Takagi N, Tsuchiya T, Honda H, Naito T, Kobari M. A study on surgical site infection surveillance (in Japanese with English abstract). Nippon Rinsho Geka (J Jpn Surg Assoc). 2007;68:527-34.

20. Tamagawa H, Takashi M, Yukawa N, Rino Y, Takanashi Y, Yamada R, et al. Postoperative complications in elderly patients with gastric cancer (in Japanese with English abstract). Nippon Rinsho Geka (J Jpn Surg Assoc). 2006;67:1186-92.

21. Braga M, Gianotti L, Nespoli L, Radaelli G, Di Carlo V. Nutritional approach in malnourished surgical patients: a prospective randomized study. Arch Surg. 2002;137:174-80. (PMID 11822956)

22. Fujitani K, Tsujinaka T, Fujita J, Miyashiro I, Imamura H, Kimura Y, et al. Prospective randomized trial of preoperative enteral immunonutrition followed by elective total gastrectomy for gastric cancer. Br J Surg. 2012;99:621-9. (PMID 22367794).

23. Gianotti L, Braga M, Nespoli L, Radaelli G, Beneduce A, Di Carlo V. A randomized controlled trial of preoperative oral supplementation with a specialized diet in patients with gastrointestinal cancer. Gastroenterology. 2002;122:1763-70. (PMID 12055582).

24. Horie H, Okada M, Kojima M, Nagai H. Favorable effects of preoperative enteral immunonutrition on a surgical site infection in patients with colorectal cancer without malnutrition. Surg Today. 2006; 36:1063-8. (PMID 17123134).

25. Aida T, Furukawa K, Suzuki D, Shimizu H, Yoshidome H, Ohtsuka M, et al. Preoperative immunonutrition decreases postoperative complications by modulating prostaglandin E2 production and T-cell differentiation in patients undergoing pancreatoduodenectomy. Surgery. 2014;155:124-33. (PMID 24589090).

26. Lindström D, Sadr Azodi O, Wladis A, et al. Effects of a perioperative smoking cessation intervention on postoperative complications: a randomized trial. Ann Surg. 2008;248:739-45. (PMID 18948800).

27. Sørensen LT, Hørby J, Friis E, et al. Smoking as a risk factor for wound healing and infection in breast cancer surgery. Eur J Surg Oncol. 2002;28:815-20. (PMID 12477471).

28. Sørensen LT, Hemmingsen U, Kallehave F, et al. Risk factors for tissue and wound complications in gastrointestinal surgery. Ann Surg. 2005;241:654-8. (PMID 15798468).

29. Goodwin SJ, McCarthy CM, Pusic AL, et al. Complications in smokers after postmastectomy tissue expander/implant breast reconstruction. Ann Plast Surg. 2005;55:16-19. (PMID 15985785).

30. Finan KR, Vick CC, Kiefe CI, et al. Predictors of wound infection in ventral hernia repair. Am J Surg. 2005;190:676-81. (PMID 16226938)

31. Bartsch RH, Weiss G, Kästenbauer T, et al. Crucial aspects of smoking in wound healing after breast reduction surgery. J Plast Reconstr Aesthet Surg. 2007;60:1045-9. (PMID 17662466). 
32. Araco F, Gravante G, Sorge R, et al. Risk evaluation of smoking and age on the occurrence of postoperative erosions after transvaginal mesh repair for pelvic organ prolapses. Int Urogynecol J Pelvic Floor Dysfunct. 2008;19:473-9. (PMID 17925992).

33. Gravante G, Araco A, Sorge R, et al. Postoperative wound infections after breast reductions: the role of smoking and the amount of tissue removed. Aesthetic Plast Surg. 2008;32:25-31. (PMID 17985175).

34. Araco A, Gravante G, Sorge R, et al. Wound infections in aesthetic abdominoplasties: the role of smoking. Plast Reconstr Surg. 2008;121:305e-310e. (PMID 18453943).

35. Watanabe A, Kohnoe S, Shimabukuro R, et al. Risk factors associated with surgical site infection in upper and lower gastrointestinal surgery. Surg Today. 2008;38:404-12. (PMID 18560962).

36. Serena-Gómez E, Passeri LA. Complications of mandible fractures related to substance abuse. J Oral Maxillofac Surg. 2008;66:2028-34. (PMID 18848098).

37. Dixon AJ, Dixon MP, Dixon JB, et al. Prospective study of skin surgery in smokers vs. nonsmokers. Br J Dermatol. 2009;160:365-7. (PMID 18945312).

38. Ogihara H, Takeuchi K, Majima Y. Risk factors of postoperative infection in head and neck surgery. Auris Nasus Larynx. 2009;36:457-60. (PMID 19111412).

39. Dahl RM, Wetterslev J, Jorgensen LN, et al. The association of perioperative dexamethasone, smoking and alcohol abuse with wound complications after laparotomy. Acta Anaesthesiol Scand. 2014;58:352-61. (PMID 24471786).

40. Manassa EH, Hertl CH, Olbrisch RR. Wound healing problems in smokers and nonsmokers after 132 abdominoplasties. Plast Reconstr Surg. 2003;111:2082-7. (PMID 12711974).

41. Padubidri AN, Yetman R, Browne E, et al. Complications of postmastectomy breast reconstructions in smokers, ex-smokers, and nonsmokers. Plast Reconstr Surg. 2001;107:342-9. (PMID 11214048).

42. Møller AM, Pedersen T, Villebro N, et al. Effect of smoking on early complications after elective orthopaedic surgery. J Bone Jt Surg Br. 2003;85:178-81. (PMID 12678348).

43. Bruggeman NB, Turner NS, Dahm DL, et al. Wound complications after open Achilles tendon repair: an analysis of risk factors. Clin Orthop Relat Res. 2004;427:63-6. (PMID 15552138).

44. Crabtree TD, Codd JE, Fraser VJ, et al. Multivariate analysis of risk factors for deep and superficial sternal infection after coronary artery bypass grafting at a tertiary care medical center. Semin Thorac Cardiovasc Surg. 2004;16:53-61. (PMID 15366688).

45. Johnston P, Gurusamy KS, Parker MJ. Smoking and hip fracture; a study of 3617 cases. Injury. 2006;37:152-6. (PMID 16243328)

46. Chan LK, Withey S, Butler PE. Smoking and wound healing problems in reduction mammaplasty: is the introduction of urine nicotine testing justified? Ann Plast Surg. 2006;56:111-5. (PMID 16432315)

47. Artioukh DY, Smith RA, Gokul K. Risk factors for impaired healing of the perineal wound after abdominoperineal resection of rectum for carcinoma. Colorectal Dis. 2007;9:362-7. (PMID 17432991).

48. Bikhchandani J, Varma SK, Henderson HP. Is it justified to refuse breast reduction to smokers? J Plast Reconstr Aesthet Surg. 2007;60:1050-4. (PMID 17512812).

49. Al-Khayat H, Al-Khayat H, Sadeq A, et al. Risk factors for wound complication in pilonidal sinus procedures. J Am Coll Surg. 2007;205:439-44. (PMID 17765160).

50. Gravante G, Araco A, Sorge R, et al. Wound infections in body contouring mastopexy with breast reduction after laparoscopic adjustable gastric bandings: the role of smoking. Obes Surg. 2008;18:721-7. (PMID 18365296).
51. Mjøen G, Øyen O, Holdaas H, et al. Morbidity and mortality in 1022 consecutive living donor nephrectomies: benefits of a living donor registry. Transplantation. 2009;88:1273-9. (PMID 19996926)

52. Araco F, Gravante G, Sorge R, et al. The influence of BMI, smoking, and age on vaginal erosions after synthetic mesh repair of pelvic organ prolapses. A multicenter study. Acta Obstet Gynecol Scand. 2009;88:772-80. (PMID 19452293).

53. Schimmel JJ, Horsting PP, de Kleuver M, et al. Risk factors for deep surgical site infections after spinal fusion. Eur Spine J. 2010;19:1711-9. (PMID 20445999).

54. Turunen P, Wikström H, Carpelan-Holmström M, et al. Smoking increases the incidence of complicated diverticular disease of the sigmoid colon. Scand J Surg. 2010;99:14-7. (PMID 20501352).

55. Karakida K1, Aoki T, Ota Y, Yamazaki H, et al. Analysis of risk factors for surgical-site infections in 276 oral cancer surgeries with microvascular free-flap reconstructions at a single university hospital. J Infect Chemother. 2010;16:334-9. (PMID 20809241).

56. Lee DH, Kim SY, Nam SY, et al. Risk factors of surgical site infection in patients undergoing major oncological surgery for head and neck cancer. Oral Oncol. 2011 47:528-31. PMID 21543250

57. Rodriguez-Argueta OF, Figueiredo R, Valmaseda-Castellon E, et al. Postoperative complications in smoking patients treated with implants: a retrospective study. J Oral Maxillofac Surg. 2011 69:2152-7. PMID 21676513

58. Sander M, Irwin M, Sinha P, et al. Suppression of interleukin-6 to interleukin-10 ratio in chronic alcoholics: association with postoperative infections. Intensive Care Med. 2002; 28:285-92. PMID 11904657

59. Delgado-Rodríguez M, Mariscal-Ortiz M, Gómez-Ortega A, et al. Alcohol consumption and the risk of nosocomial infection in general surgery. Br J Surg. 2003; 90:1287-93. PMID 14515302

60. Spies CD, von Dossow V, Eggers V, et al. Altered cell-mediated immunity and increased postoperative infection rate in long-term alcoholic patients. Anesthesiology. 2004; 100:1088-100. PMID 15114205

61. Bertelsen CA, Andreasen AH, Jørgensen T, et al. Anastomotic leakage after anterior resection for rectal cancer: risk factors. Colorectal Dis. 2010; 12:37-43. PMID 19175624

62. Daneman N, Lu H, Redelmeier DA. Discharge after discharge: predicting surgical site infections after patients leave hospital. J Hosp Infect. 2010; 75:188-94. PMID 20435375

63. Bradley KA, Rubinsky AD, Sun H, et al. Alcohol screening and risk of postoperative complications in male VA patients undergoing major non-cardiac surgery. J Gen Intern Med. 2011; 26:162-9. PMID 20878363

64. Tonnesen H, Rosenberg J, Nielsen HJ, et al. Effect of preoperative abstinence on poor postoperative outcome in alcohol misusers: randomised controlled trial. BMJ. 1999; 318:1311-6. PMID 10323814

65. Tay GS, Binion DG, Eastwood D, et al. Multivariate analysis suggests improved perioperative outcome in Crohn's disease patients receiving immunomodulator therapy after segmental resection and/or strictureplasty. Surgery. 2003 134:565-72. PMID 14605616

66. Marchal L, D’Haens G, Van Assche G, et al. The risk of postoperative complications associated with infliximab therapy for Crohn's disease: a controlled cohort study. Aliment Pharmacol Ther. 2004 19:749-54.PMID 15043515

67. Ferrante M, D'Hoore A, Vermeire S, et al. Corticosteroids but not infliximab increase short-term postoperative infectious complications in patients with ulcerative colitis. Inflamm Bowel Dis. 2009 15:1062-70. PMID 19161179 
68. Nasir BS, Dozois EJ, Cima RR, et al. Perioperative anti-tumor necrosis factor therapy does not increase the rate of early postoperative complications in Crohn's disease. J Gastrointest Surg. 2010 14:1859-65. PMID 20872084

69. Canedo J, Lee SH, Pinto R, et al. Surgical resection in Crohn's disease: is immunosuppressive medication associated with higher postoperative infection rates? Colorectal Dis. 2011 13:1294-8. PMID 20969715

70. Gainsbury ML, Chu DI, Howard LA, et al, Preoperative infliximab is not associated with an increased risk of short-term postoperative complications after restorative proctocolectomy and ileal pouch-anal anastomosis. J Gastrointest Surg. 2011 15:397-403.PMID 21246215

71. Bregnbak D, Mortensen C, Bendtsen F. Infliximab and complications after colectomy in patients with ulcerative colitis. J Crohns Colitis. 2012 6:281-6. PMID 22405163

72. Syed A, Cross RK, Flasar MH. Anti-tumor necrosis factor therapy is associated with infections after abdominal surgery in Crohn's disease patients. Am J Gastroenterol. 2013 108:583-93. PMID 23481144

73. Gu J, Remzi FH, Shen B, et al. Operative strategy modifies risk of pouch-related outcomes in patients with ulcerative colitis on preoperative anti-tumor necrosis factor- $\alpha$ therapy. Dis Colon Rectum. 2013 56:1243-52. PMID 24104999

74. Nelson R, Liao C, Fichera A, et al. Rescue therapy with cyclosporine or infliximab is not associated with an increased risk for postoperative complications in patients hospitalized for severe steroid-refractory ulcerative colitis. Inflamm Bowel Dis. 2014 20:14-20. PMID 24297054

75. Colombel JF, Loftus EV Jr, Tremaine WJ, et al. Early postoperative complications are not increased in patients with Crohn's disease treated perioperatively with infliximab or immunosuppressive therapy. Am J Gastroenterol. 2004 May;99(5):878-83. PMID 15128354

76. Appau KA, Fazio VW, Shen B, et al. Use of infliximab within 3 months of ileocolonic resection is associated with adverse postoperative outcomes in Crohn's patients. J Gastrointest Surg. 2008 12:1738-44. PMID 18709420

77. Schaufler C, Lerer T, Campbell B, et al. Preoperative immunosuppression is not associated with increased postoperative complications following colectomy in children with colitis. J Pediatr Gastroenterol Nutr. 2012 55:421-4. PMID 22395189

78. Uchino M, Ikeuchi $\mathrm{H}$, Matsuoka $\mathrm{H}$, et al. Infliximab administration prior to surgery does not increase surgical site infections in patients with ulcerative colitis. Int J Colorectal Dis. 2013 28:1295-306. PMID 23604447

79. Ahn HS, Lee SK, Kim HJ, et al. Risk of postoperative infection in patients with inflammatory bowel disease. Korean J Gastroenterol. 2006 48:306-12. PMID 17132918

80. Miki C, Ohmori Y, Yoshiyama S, et al. Factors predicting postoperative infectious complications and early induction of inflammatory mediators in ulcerative colitis patients. World J Surg. 2007 31:522-9. PMID 17334865

81. Miettinen RP, Laitinen ST, Mäkelä JT, et al, Bowel preparation with oral polyethylene glycol electrolyte solution vs. no preparation in elective open colorectal surgery: prospective, randomized study. Dis Colon Rectum. 2000 43:669-75. PMID 10826429

82. Bucher P, Gervaz P, Soravia C, et al. Randomized clinical trial of mechanical bowel preparation versus no preparation before elective left-sided colorectal surgery. Br J Surg. 2005 92:409-14. PMID 15786427

83. Fa-Si-Oen P, Roumen R, Buitenweg J, et al. Mechanical bowel preparation or not? Outcome of a multicenter, randomized trial in elective open colon surgery. Dis Colon Rectum. 2005 48:150916. PMID 15981065
84. Platell C, Barwood N, Makin G. Randomized clinical trial of bowel preparation with a single phosphate enema or polyethylene glycol before elective colorectal surgery. Br J Surg. 2006 93:427-33. PMID 16491463

85. Zmora O, Mahajna A, Bar-Zakai B, et al. Is mechanical bowel preparation mandatory for left-sided colonic anastomosis? Results of a prospective randomized trial. Tech Coloproctol. 2006 10:131-5. PMID 16773286

86. Jung B, Påhlman L, Nyström PO, et al. Multicentre randomized clinical trial of mechanical bowel preparation in elective colonic resection. Br J Surg. 2007 94:689-95. PMID 17514668

87. Contant CM, Hop WC, van't Sant HP, et al. Mechanical bowel preparation for elective colorectal surgery: a multicentre randomised trial. Lancet. 2007 370:2112-7. PMID 18156032

88. Pena-Soria MJ, Mayol JM, Anula R, et al. Single-blinded randomized trial of mechanical bowel preparation for colon surgery with primary intraperitoneal anastomosis. J Gastrointest Surg. 2008 12:2103-8. PMID 18820977

89. Bretagnol F, Panis Y, Rullier E, et al. Rectal cancer surgery with or without bowel preparation: The French GRECCAR III multicenter single-blinded randomized trial. Ann Surg. 2010 252:863-8. PMID 21037443

90. Bertani E, Chiappa A, Biffi R, et al. Comparison of oral polyethylene glycol plus a large volume glycerine enema with a large volume glycerine enema alone in patients undergoing colorectal surgery for malignancy: a randomized clinical trial. Colorectal Dis. 2011 13:e327-34. PMID 21689356

91. Kale TI, Kuzu MA, Tekeli A, et al. Aggressive bowel preparation does not enhance bacterial translocation, provided the mucosal barrier is not disrupted: a prospective, randomized study. Dis Colon Rectum. 1998 41:636-41. PMID 9593249

92. Ishida H, Yokoyama M, Nakada H, et al. Impact of oral antimicrobial prophylaxis on surgical site infection and methicillinresistant Staphylococcus aureus infection after elective colorectal surgery. Results of a prospective randomized trial. Surg Today. 2001 31:979-83. PMID 11766085

93. Lewis RT. Oral versus systemic antibiotic prophylaxis in elective colon surgery: a randomized study and meta-analysis send a message from the 1990s. Can J Surg. 2002 45:173-80. PMID 12067168

94. Espin-Basany E, Sanchez-Garcia JL, Lopez-Cano M, et al. Prospective, randomised study on antibiotic prophylaxis in colorectal surgery. Is it really necessary to use oral antibiotics? Int J Colorectal Dis. 2005 20:542-6. PMID 15843938

95. Kobayashi M, Mohri Y, Tonouchi H, et al. Randomized clinical trial comparing intravenous antimicrobial prophylaxis alone with oral and intravenous antimicrobial prophylaxis for the prevention of a surgical site infection in colorectal cancer surgery. Surg Today. 2007 37:383-8. PMID 17468819

96. Oshima T, Takesue Y, Ikeuchi H, et al. Preoperative oral antibiotics and intravenous antimicrobial prophylaxis reduce the incidence of surgical site infections in patients with ulcerative colitis undergoing IPAA. Dis Colon Rectum. 2013 56:1149-55. PMID 24022532

97. Sadahiro S, Suzuki T, Tanaka A, et al. Comparison between oral antibiotics and probiotics as bowel preparation for elective colon cancer surgery to prevent infection: prospective randomized trial. Surgery. 2014 155:493-503. PMID 24524389

98. Hata H, Yamaguchi T, Hasegawa S, et al. Oral and Parenteral Versus Parenteral Antibiotic Prophylaxis in Elective Laparoscopic Colorectal Surgery (JMTO PREV 07-01): A Phase 3, Multicenter, Open-label, Randomized Trial. Ann Surg. 2016 263:1085-91. PMID 26756752

99. Ikeda A, Konishi T, Ueno M, et al. Randomized clinical trial of oral and intravenous versus intravenous antibiotic prophylaxis 
for laparoscopic colorectal resection. Br J Surg. 2016 103:1608_ 1615 PMID 27550722

100. Uchino M, Ikeuchi H, Bando T, et al. Efficacy of Preoperative Oral Antibiotic Prophylaxis for the Prevention of Surgical Site Infections in Patients with Crohn Disease: A Randomized Controlled Trial. Ann Surg. 2017 [Epub ahead of print] PMID 29064884

101. Kim EK, Sheetz KH, Bonn J, et al. A statewide colectomy experience: the role of full bowel preparation in preventing surgical site infection. Ann Surg. 2014 259:310-4. PMID 23979289

102. Morris MS, Graham LA, Chu DI, et al. Oral Antibiotic Bowel Preparation Significantly Reduces Surgical Site Infection Rates and Readmission Rates in Elective Colorectal Surgery. Ann Surg. 2015 261:1034-40. PMID 25607761

103. Wells FC, Newsom SW, Rowlands C. Wound infection in cardiothoracic surgery. Lancet. 1983 1:1209-10. PMID 6134001

104. Leigh DA, Stronge JL, Marriner J, et al. Total body bathing with 'Hibiscrub' (chlorhexidine) in surgical patients: a controlled trial. J Hosp Infect. 1983 4:229-35. PMID 6195235

105. Ayliffe GA, Noy MF, Babb JR, et al. A comparison of pre-operative bathing with chlorhexidine-detergent and non-medicated soap in the prevention of wound infection. J Hosp Infect. 1983 4:237-44. PMID 6195236

106. Randall PE, Ganguli L, Marcuson RW. Wound infection following vasectomy. Br J Urol. 1983 55:564-7. PMID 6626903

107. Hayek LJ, Emerson JM, Gardner AM. A placebo-controlled trial of the effect of two preoperative baths or showers with chlorhexidine detergent on postoperative wound infection rates. J Hosp Infect. 1987 10:165-72. PMID 2889770

108. Rotter ML, Larsen SO, Cooke EM, et al. A comparison of the effects of preoperative whole-body bathing with detergent alone and with detergent containing chlorhexidine gluconate on the frequency of wound infections after clean surgery. The European Working Party on Control of Hospital Infections. J Hosp Infect. 1988 11:310-20. PMID 2899582

109. Earnshaw JJ, Berridge DC, Slack RC, et al. Do preoperative chlorhexidine baths reduce the risk of infection after vascular reconstruction? Eur J Vasc Surg. 1989 3:323-6. PMID 2670608

110. Byrne DJ, Phillips G, Napier A, et al. The effect of whole body disinfection on intraoperative wound contamination. J Hosp Infect. 1991 18:145-8.PMID1678760

111. Lynch W, Davey PG, Malek M, et al. Cost-effectiveness analysis of the use of chlorhexidine detergent in preoperative whole-body disinfection in wound infection prophylaxis. J Hosp Infect. 1992 21:179-91. PMID 1353510

112. Veiga DF, Damasceno CA, Veiga-Filho J, et al. Randomized controlled trial of the effectiveness of chlorhexidine showers before elective plastic surgical procedures. Infect Control Hosp Epidemiol. 2009 30:77-9. PMID 19046051

113. Abouzari M, Sodagari N, Hasibi M, Re: Nonshaved cranial surgery in black Africans: a short-term prospective preliminary study (Adeleye and Olowookere, Surg Neurol 2008;69-72) Effect of hair on surgical wound infection after cranial surgery: a 3-armed randomized clinical trial. Surg Neurol. 2009 71:261-2; author reply 262. PMID 18440617

114. Alexander JW, Fischer JE, Boyajian M, et al. The influence of hair-removal methods on wound infections. Arch Surg. 1983 118:347-52. PMID 682443

115. Balthazar ER, Colt JD, Nichols RL. Preoperative hair removal: a random prospective study of shaving versus clipping. South Med J. 1982 75:799-801. PMID 7089645

116. Grober ED, Domes T, Fanipour M, Preoperative hair removal on the male genitalia: clippers vs. razors. J Sex Med. 2013 10:58994. PMID 22908852
117. Ko W, Lazenby WD, Zelano JA, Effects of shaving methods and intraoperative irrigation on suppurative mediastinitis after bypass operations. Ann Thorac Surg. 1992 53:301-5. PMID 1731672

118. Meiland HT, Feder E, Rosen $\varnothing$ H. Episiotomy infections after shaving or cutting Ugeskr Laeger. 1986 148:2481-2. PMID 3775942

119. Taylor T, Tanner J. Razors versus clippers. A randomised controlled trial. Br J Perioper Nurs. 2005 15:518-20, 522-3. PMID 16372777

120. Adisa AO, Lawal OO, Adejuyigbe O. Evaluation of two methods of preoperative hair removal and their relationship to postoperative wound infection. J Infect Dev Ctries. 2011 5:717-22. PMID 21997940

121. Court-Brown CM. Preoperative skin depilation and its effect on postoperative wound infections. J R Coll Surg Edinb. 1981 26:238-41. PMID 70218125

122. Powis SJ, Waterworth TA, Arkell DG. Preoperative skin preparation: clinical evaluation of depilatory cream. Br Med J. 1976 2:1166-8. PMID 791444

123. Seropian R, Reynolds BM. Wound infections after preoperative depilatory versus razor preparation. Am J Surg. 1971 121:251-4. PMID 546329

124. Thur de Koos P, McComas B. Shaving versus skin depilatory cream for preoperative skin preparation. A prospective study of wound infection rates. Am J Surg. 1983 145:377-8. PMID 6837864

125. Nascimento JEA, Caporossi C, Marra JG, et al, Influence of preoperative shaving in wound infections of clean operations. Arquivos Brasileiros de Medicina 1991 65:157-9.PMID 不明

126. Celik SE, Kara A. Does shaving the incision site increase the infection rate after spinal surgery? Spine (Phila Pa 1976). 2007 32:1575-7. PMID 17621202

127. Kattipattanapong W, Isaradisaikul S, Hanprasertpong C. Surgical site infections in ear surgery: hair removal effect; a preliminary, randomized trial study. Otolaryngol Head Neck Surg. 2013 148:469-74. PMID 23283828

128. Rojanapirom S, Danchaivijitr S. Pre-operative shaving and wound infection in appendectomy. J Med Assoc Thai. 1992;75(Suppl):2.

129. Tocchi A, Lepre L, Costa G, et al. The need for antibiotic prophylaxis in elective laparoscopic cholecystectomy: a prospective randomized study. Arch Surg 2000;135:67-70; discussion 70.

130. Mahatharadol V. A reevaluation of antibiotic prophylaxis in laparoscopic cholecystectomy: a randomized controlled trial. J Med Assoc Thai. 2001;84:105-8.

131. Guzman-Valdivia G. Routine administration of antibiotics to patients suffering accidental gallbladder perforation during laparoscopic cholecystectomy is not necessary. Surg Laparosc Endosc Percutan Tech. 2008;18:547-50.

132. Uludag M, Yetkin G, Citgez B. The role of prophylactic antibiotics in elective laparoscopic cholecystectomy. JSLS. 2009;13:337-41.

133. Yildiz B, Abbasoglu O, Tirnaksiz B, et al. Determinants of postoperative infection after laparoscopic cholecystectomy. Hepatogastroenterology. 2009;56:589-92.

134. Sharma N, Garg PK, Hadke NS, et al. Role of prophylactic antibiotics in laparoscopic cholecystectomy and risk factors for surgical site infection: a randomized controlled trial. Surg Infect (Larchmt). 2010;11:367-70.

135. Hassan AM, Nasr MM, Hamdy HE, et al. Role of prophylactic antibiotic in elective laparoscopic cholecystectomy. J Egypt Soc Parasitol. 2012;42:129-34.

136. Shah JN, Maharjan SB, Paudyal S. Routine use of antibiotic prophylaxis in low-risk laparoscopic cholecystectomy is unnecessary: a randomized clinical trial. Asian J Surg. 2012;35:136-9. 
137. Naqvi MA, Mehraj A, Ejaz R, et al. Role of prophylactic antibiotics in low risk elective laparoscopic cholecystectomy: is there a need? J Ayub Med Coll Abbottabad. 2013;25:172-4.

138. Turk E, Karagulle E, Serefhanoglu K, et al. Effect of cefazolin prophylaxis on postoperative infectious complications in elective laparoscopic cholecystectomy: a prospective randomized study. Iran Red Crescent Med J. 2013;15:581-6.

139. Matsui Y, Satoi S, Kaibori M, et al. Antibiotic prophylaxis in laparoscopic cholecystectomy: a randomized controlled trial. PLoS ONE. 2014;9:e106702.

140. Ruangsin S, Laohawiriyakamol S, Sunpaweravong S, et al. The efficacy of cefazolin in reducing surgical site infection in laparoscopic cholecystectomy: a prospective randomized double-blind controlled trial. Surg Endosc. 2015;29:874-81.

141. Sarkut P, Kilicturgay S, Aktas H, et al. Routine Use of Prophylactic Antibiotics during Laparoscopic Cholecystectomy Does Not Reduce the Risk of Surgical Site Infections. Surg Infect (Larchmt). 2017;18:603-9.

142. Kasatpibal N, Norgaard M, Sorensen HT, et al. Risk of surgical site infection and efficacy of antibiotic prophylaxis: a cohort study of appendectomy patients in Thailand. BMC Infect Dis. 2006;6:111.

143. Koch CG, Li L, Hixson E, et al. Is it time to refine? An exploration and simulation of optimal antibiotic timing in general surgery. J Am Coll Surg. 2013;217:628-35.

144. Wu WT, Tai FC, Wang PC, et al. Surgical site infection and timing of prophylactic antibiotics for appendectomy. Surg Infect (Larchmt). 2014;15:781-5.

145. Mohri Y, Tonouchi H, Kobayashi M, et al. Randomized clinical trial of single- versus multiple-dose antimicrobial prophylaxis in gastric cancer surgery. Br J Surg. 2007;94:683-8.

146. Haga N, Ishida $\mathrm{H}$, Ishiguro $\mathrm{T}$, et al. A prospective randomized study to assess the optimal duration of intravenous antimicrobial prophylaxis in elective gastric cancer surgery. Int Surg. 2012;97:169-76.

147. Imamura $H$, Kurokawa $Y$, Tsujinaka $T$, et al. Intraoperative versus extended antimicrobial prophylaxis after gastric cancer surgery: a phase 3, open-label, randomised controlled, non-inferiority trial. Lancet Infect Dis. 2012;12:381-7.

148. Surgical site infection: evidence update 43 (June 2013). London: National Institute for Health and Care Excellence (NICE), 2013. http://www.nice.org.uk/guidance/cg74/evidence/evidence-updat e-241969645

149. Anderson DJ, Podgorny K, Berríos-Torres SI, et al. Strategies to prevent surgical site infections in acute care hospitals: 2014 update. Infect Control Hosp Epidemiol. 2014;35:605-27 ((PMID: 24799638)).

150. WHO (World Health Organization). Global guidelines for the prevention of surgical site infection. http://apps.who.int/iris/bitst ream/10665/250680/1/9789241549882-eng.pdf. Accessed 4 Aug 2020.

151. Parienti JJ, Thibon P, Heller R, et al. Antisepsie Chirurgicale des mains Study Group. Hand-rubbing with an aqueous alcoholic solution vs traditional surgical hand-scrubbing and 30-day surgical site infection rates: a randomized equivalence study. JAMA. 2002;288:722-7.

152. Al-Naami MY, Anjum MN, Afzal MF, et al. Alcohol-based handrub versus traditional surgical scrub and the risk of surgical site infection: a randomized controlled equivalent trial. EWMA J. 2009;9:5-10.

153. Nthumba PM, Stepita-Poenaru E, Poenaru D, et al. Clusterrandomized, crossover trial of the efficacy of plain soap and water versus alcohol-based rub for surgical hand preparation in a rural hospital in Kenya. Br J Surg. 2010;97:1621-8 ((PMID:20878941)).
154. Marchand R, Theoret S, Dion D, et al. Clinical implementation of a scrubless chlorhexidine/ethanol pre-operative surgical hand rub. Can Oper Room Nurs J. 2008;26:21-2 ((PMID: 18678198)).

155. Adjoussou S, Konan Blé R, Séni K, et al. Value of hand disinfection by rubbing with alcohol prior to surgery in a tropical setting. Med Trop (Mars). 2009;69:463-6 ((Article in French]: PMID: 20025174)).

156. Fukada T, Fujii A. A comparison study of surgical site infection rates by hand-rubbing vs traditional hand-scrubbing for handwashing during surgery. Surgery. 2008;70:261-5 ((in Japanese with English Abstract)).

157. Hajipour L, Longstaff L, Cleeve V, et al. Hand washing rituals in trauma theatre: clean or dirty? Ann R Coll Surg Engl. 2006;88:13-5 ((PMID: 16460630)).

158. Sakai K, Iizuka M, Kimoto H. Analysis of the effects of introducing the rubbing method: from the viewpoint of economy (cost) and SSI. J Jpn Soc Open Med. 2010;31:358-60 ((No English Abstract)).

159. Yanagomoto M, Sakai K, Ohshiro T, et al. Comparative study of hand washing method in operating room of a hospital: comparison of the waterless method and the scrub rubbing two-step method. Abstr Okinawa Prefect Nurs Res Assoc. 2012;28:93-6 ((No English Abstract)).

160. Sistla SC, Prabhu G, Sistla S, et al. Minimizing wound contamination in a "clean" surgery: comparison of chlorhexidine-ethanol and povidone-iodine. Chemotherapy. 2010;56:261-7.

161. Darouiche RO, Wall MJ Jr, Itani KM, Awad SS, Crosby CT, Mosier MC, Alsharif A, Berger DH, et al. Chlorhexidine-alcohol versus povidone-iodine for surgical-site antisepsis. N Engl J Med. 2010;362:18-26.

162. Srinivas A, Kaman L, Raj P, et al. Comparison of the efficacy of chlorhexidine gluconate versus povidone iodine as preoperative skin preparation for the prevention of surgical site infections in clean-contaminated upper abdominal surgeries. Surg Today. 2015;45:1378-84.

163. Harihara Y, Ito M, Oe M, Katayama M. A phase III clinical study of novel antiseptic, OPB-2045G solution (Olanedine Antiseptic solu- tion 1.5\%). J Jpn Soc Surg Infect 2015;12:137-148.

164. Jackson DW, Pollock AV, Tindal DS. The value of a plastic adhesive drape in the prevention of wound infection. A controlled trial. British Journal of Surgery 1971;58: 340-342.

165. Psaila JV, Wheeler MH, Crosby DL. The role of plastic wound drapes in the prevention of wound infection following abdominal surgery. Br J Surg. 1977;64:729-32.

166. Dewan PA, Van Rij AM, Robinson RG, et al. The use of an iodophor-impregnated plastic incise drape in abdominal surgery - a controlled clinical trial. Aust N Z J Surg. 1987;57:859-63.

167. Yoshimura Y, Kubo S, Hirohashi K, Ogawa M, Morimoto K, Shirata K, Kinoshita H. Plastic iodophor drape during liver surgery operative use of the iodophor-impregnated adhesive drape to prevent wound infection during high risk surgery. World J Surg. 2003;27(6):685-8.

168. Lauscher JC, Grittner F, Stroux A, et al. Reduction of wound infections in laparoscopic-assisted colorectal resections by plastic wound ring drapes (REDWIL)? A randomized controlled trial. Langenbecks Arch Surg. 2012;397:1079-85.

169. Baier P, Kiesel M, Kayser C, et al. Ring drape do not protect against surgical site infections in colorectal surgery: a randomised controlled study. Int J Colorectal Dis. 2012;27:1223-8.

170. Cheng KP, Roslani AC, Sehha N, et al. ALEXIS O-Ring wound retractor vs conventional wound protection for the prevention of surgical site infections in colorectal resections. Colorectal Dis. 2012;14:e346-51.

171. Reid K, Pockney P, Draganic B, et al. Barrier wound protection decreases surgical site infection in open elective 
colorectal surgery: a randomized clinical trial. Dis Colon Rectum. 2010;53:1374-80.

172. Horiuchi T, Tanishima H, Tamagawa K, et al. Randomized, controlled investigation of the anti-infective properties of the Alexis retractor/protector of incision sites. J Trauma. 2007;62:212-5.

173. Lee P, Waxman K, Taylor B, et al. Use of wound-protection system and postoperative wound-infection rates in open appendectomy: a randomized prospective trial. Arch Surg. 2009;144:872-5.

174. Mihaljevic AL, Schirren R, Özer M, et al. Multicenter doubleblinded randomized controlled trial of standard abdominal wound edge protection with surgical dressings versus coverage with a sterile circular polyethylene drape for prevention of surgical site infections: a CHIR-Net trial (BaFO; NCT01181206). Ann Surg. 2014;260:730-7.

175. Pinkney TD, Calvert M, Bartlett DC, Gheorghe A, Redman V, Dowswell G, Hawkins W, Mak T, Youssef H, Richardson C, Hornby S, Magill L, Haslop R, Wilson S, Morton D; West Midlands Research Collaborative; ROSSINI Trial Investigators. Impact of wound edge protection devices on surgical site infection after laparotomy: multicentre randomised controlled trial (ROSSINI Trial). BMJ. 2013;347:f4305.

176. Gheorghe A, Roberts TE, Pinkney TD, Bartlett DC, Morton D, Calvert M; West Midlands Research Collaborative; ROSSINI Trial Investigators. The cost-effectiveness of wound-edge protection devices compared to standard care in reducing surgical site infection after laparotomy: an economic evaluation alongside the ROSSINI trial. PLoS One. 2014 18;9:e95595.

177. Gani JS, Anseline PF, Bissett RL. Efficacy of double versus single gloving in protecting the operating team. Aust N Z J Surg. 1990;60:171-5 (PMID: 2327922).

178. Jensen SL, Kristensen B, Fabrin K. Double gloving as self protection in abdominal surgery. Eur J Surg. 1997;163:163-7 (PMID: 9085056).

179. Thomas S, Agarwal M, Mehta G. Intraoperative glove perforation - single versus double gloving in protection against skin contamination. Postgrad Med J. 2001;77:458-60 (PMID: 11423598).

180. Wilson SJ, Sellu D, Uy A, et al. Subjective effects of double gloves on surgical performance. Ann R Coll Surg Engl. 1996;78:20-2 (PMID: 8659967).

181. Naver LP, Gottrup F. Incidence of glove perforations in gastrointestinal surgery and the protective effect of double gloves: a prospective randomised controlled study. Eur J Surg. 2000;166:293-5 (PMID: 10817324).

182. Ortiz H, Armendariz P, Kreisler E, et al. Influence of rescrubbing before laparotomy closure on abdominal wound infection after colorectal cancer surgery: results of a multicenter randomized clinical trial. Arch Surg. 2012;147:614-20 (PMID: 22430092).

183. Nakamura T, Kashimura N, Niji T, et al. Triclosan-coated sutures reduce the incidence of wound infections and the costs after colorectal surgery: a randomized controlled trial. Surgery. 2013;153:576-83 (PMID: 23261025).

184. Mingmalairak C, Ungbhakorn P, Paocharoen V. Efficacy of antimicrobial coating suture coated polyglactin 910 with tricosan (Vicryl plus) compared with polyglactin 910 (Vicryl) in reduced surgical site infection of appendicitis, double blind randomized control trial, preliminary safety report. J Med Assoc Thai. 2009;92:770-5 (PMID: 19530582).

185. Rasić Z, Schwarz D, Adam VN, et al. Efficacy of antimicrobial triclosan-coated polyglactin 910 (Vicryl* Plus) suture for closure of the abdominal wall after colorectal surgery. Coll Antropol. 2011;35:439-43 (PMID: 21755716).

186. Baracs J, Huszár O, Sajjadi SG, et al. Surgical site infections after abdominal closure in colorectal surgery using triclosancoated absorbable suture (PDS Plus) vs. uncoated sutures (PDS
II): a randomized multicenter study. Surg Infect (Larchmt). 2011;12:483-489. PMID: 22142314

187. Justinger C, Slotta JE, Ningel S, et al. Surgical-site infection after abdominal wall closure with triclosan-impregnated polydioxanone sutures: results of a randomized clinical pathway facilitated trial (NCT00998907). Surgery. 2013;154:589-95 (PMID: 23859304)

188. Diener MK, Knebel P, Kieser M, et al. Effectiveness of triclosancoated PDS Plus versus uncoated PDS II sutures for prevention of surgical site infection after abdominal wall closure: the randomised controlled PROUD trial. Lancet. 2014;12(384):142-52 (PMID: 24718270).

189. Mattavelli I, Rebora P, Doglietto G, et al. Multi-Center Randomized Controlled Trial on the Effect of Triclosan-Coated Sutures on Surgical Site Infection after Colorectal Surgery. Surg Infect (Larchmt). 2015;16:226-35 (PMID: 25811951).

190. Ruiz-Tovar J, Alonso N, Morales V, et al. Association between Triclosan-Coated Sutures for Abdominal Wall Closure and Incisional Surgical Site Infection after Open Surgery in Patients Presenting with Fecal Peritonitis: A Randomized Clinical Trial. Surg Infect (Larchmt). 2015;16:588-94 (PMID: 26171624).

191. Umemura A, Suto T, Nakamura S, et al. Does antimicrobial triclosan-coated PDS PLUS or subcutaneous closure reduce surgical site infections?, A controlled clinical trial of class Il abdominal surgeries. Nihon Geka Kannsennshou Gakkai Zasshi. 2016;13:265-270. IchuWebID 2017058141

192. Renko M, Paalanne N, Tapiainen T, et al. Triclosan-containing sutures versus ordinary sutures for reducing surgical site infections in children: a double-blind, randomized controlled trial. Lancet Infect Dis. 2017;17:50-7 (PMID: 27658562).

193. H Matsumoto, R Kawabata, H Imamura, et al. Impact of the use of triclosan-coated antibacterial sutures on the incidence of surgical site infections after gastric cancer surgery. Ichiritsusakaibyouin Igaku Zasshi. 2012;14:2-6. Ichushi-web ID 2012333668

194. Hoshino S, Yoshida Y, Tanimura S, et al. A study of the efficacy of antibacterial sutures for surgical site infection: a retrospective controlled trial. Int Surg. 2013;98:129-32 (PMID: 23701147).

195. Okada N, Nakamura T, Ambo Y, et al. Triclosan-coated abdominal closure sutures reduce the incidence of surgical site infections after pancreaticoduodenectomy. Surg Infect (Larchmt). 2014;15:305-9 (PMID: 24797228).

196. Fraccalvieri D, Kreisler Moreno E, Flor Lorente B, et al. Predictors of wound infection in elective colorectal surgery. Multicenter observational case-control study Cir Esp. 2014;92:478-84 (PMID: 24439490).

197. Nakamura T, Sato T, Takayama Y, et al. Risk Factors for Surgical Site Infection after Laparoscopic Surgery for Colon Cancer. Surg Infect (Larchmt). 2016;17:454-8 (PMID: 27027328).

198. Uchino M, Mizuguchi T, Ohge H, et al. The Efficacy of Antimicrobial-Coated Sutures for Preventing Incisional Surgical Site Infections in Digestive Surgery: a Systematic Review and Metaanalysis. J Gastrointest Surg. 2018. [Epub ahead of print] PMID: 29926317

199. Cervantes-Sanchez CR, Gutierrez-Vega R, Vazquez-Carpizo JA, et al. Syringe pressure irrigation of subdermic tissue after appendectomy to decrease the incidence of postoperative wound infection. World J Surg. 2000;24:38-41 (PMID: 10594201).

200. Mueller TC, Loos M, Haller B, et al. Intra-operative wound irrigation to reduce surgical site infections after abdominal surgery: a systematic review and meta-analysis. Langenbecks Arch Surg. 2015;400:167-81 (PMID: 25681239).

201. Nikfarjam M, Weinberg L, Fink MA, et al. Pressurized pulse irrigation with saline reduces surgical-site infections following major hepatobiliary and pancreatic surgery: randomized controlled trial. World J Surg. 2014;38:447-55 (PMID: 24170152). 
202. Nikfarjam M, Kimchi ET, Gusani NJ, et al. Reduction of surgical site infections by use of pulsatile lavage irrigation after prolonged intra-abdominal surgical procedures. Am J Surg. 2009;198:381-6 (PMID: 19344885).

203. Ozaki A, Kume M. Syringe pressure irrigation, easy device remodeling to reduce superficial incisional surgical site infection (in Japanese with English abstract). Nihon Kankyokansen Gakkaizasshi (Jpn J of Infection Control and Prevention). 2013;28:7-12.

204. Dineen SP, Pham TH, Murray BW, et al. Feasibility of subcutaneous gentamicin and pressurized irrigation as adjuvant strategies to reduce surgical site infection in colorectal surgery: results of a pilot study. Am Surg. 2015;81:573-9 (PMID: 26031269).

205. Kubota A, Goda T, Tsuru T, et al. Efficacy and safety of strong acid electrolyzed water for peritoneal lavage to prevent surgical site infection in patients with perforated appendicitis. Surg Today. 2015;45:876-9 (PMID: 25387655).

206. Takesue Y, Takahashi Y, Ichiki K, et al. Application of an electrolyzed strongly acidic aqueous solution before wound closure in colorectal surgery. Dis Colon Rectum. 2011;54:826-32 (PMID: 21654249).

207. Tanaka K, Matsuo K, Kawaguchi D, et al. Randomized clinical trial of peritoneal lavage for preventing surgical site infection in elective liver surgery. J Hepatobiliary Pancreat Sci. 2015;22:44653 (PMID: 25611190).

208. St Peter SD, Adibe OO, Iqbal CW, et al. Irrigation versus suction alone during laparoscopic appendectomy for perforated appendicitis: a prospective randomized trial. Ann Surg. 2012;256:581-5 (PMID: 22964730).

209. Snow HA, Choi JM, Cheng MW, et al. Irrigation versus suction alone during laparoscopic appendectomy; A randomized controlled equivalence trial. Int J Surg. 2016;28:91-6 (PMID: 26912015).

210. Akkoyun I, Tuna AT. Advantages of abandoning abdominal cavity irrigation and drainage in operations performed on children with perforated appendicitis. J Pediatr Surg. 2012;47:1886-90 (PMID: 23084202).

211. Moore CB, Smith RS, Herbertson R, et al. Does use of intraoperative irrigation with open or laparoscopic appendectomy reduce post-operative intra-abdominal abscess? Am Surg. 2011;77:7880 (PMID: 21396311).

212. Kim J, Lee J, Hyung WJ, Cheong JH, Chen J, Choi SH, Noh SH. Gastric cancer surgery without drains:a prospective randomized trial. J Gastrointest Surg. 2004;8:727-32.

213. Álvarez Uslar R, Molina H, Torres O, Cancino A. Total gastrectomy with or without abdominal drains. A prospective randomized trial. Rev Esp Enferm Dig. 2005;97:562-9.

214. Kumar M, Yang SB, Jaiswal VK, Shah JN, Shreshtha M, Gongal R. Is prophylactic placement of drains necessary after subtotal gastrectomy? World J Gastroenterol. 2007;13:3738-41.

215. Hirahara N, Matsubara T, Hayashi H, Takai K, Fujii Y, Tajima Y. Significance of prophylactic intra-abdominal drain placement after laparoscopic distal gastrectomy for gastric cancer. World $\mathbf{J}$ Surg Oncol. 2015;13:181.

216. Dann GC, Squires MH 3rd, Postlewait LM, Kooby DA, Poultsides GA, Weber SM, Bloomston M, et al. Value of peritoneal drain placement after total gastrectomy for gastric adenocarcinoma: a multi-institutional analysis from the US gastric cancer collaborative. Ann Surg Oncol. 2015;22:S888-97.

217. Capitanich P, Segundo UL, Malizia P, Herrera J, Iovaldi ML. Usefulness of prophylactic drainage in laparoscopic cholecystectomy. Randomized prospective report. Prensa Med Argentina. 2005;92:623-7.

218. Mrozowicz A, Rucinski P, Polkowski WP. Routine drainage of the subhepatic area after laparoscopic cholecystectomy.
Prospective, controlled study with random patient selection. Polski Przeglad Chirurgiczny 2006; 78: 597-609.

219. Uchiyama K, Tani M, Kawai M, Terasawa H, Hama T, Yamaue $\mathrm{H}$. Clinical significance of drainage tube insertion in laparoscopic cholecystectomy: a prospective randomized controlled trial. J Hepatobiliary Pancreat Surg. 2007;14:551-6.

220. Tzovaras G, Liakou P, Fafoulakis F, Baloyiannis I, Zacharoulis $\mathrm{D}$, Hatzitheofilou C. Is there a role for drain use in elective laparoscopic cholecystectomy? A controlled randomized trial. Am J Surg. 2009;197:759-63.

221. Georgiou C, Demetriou N, Pallaris T, Theodosopoulos T, Katsouyanni K, Polymeneas G. Is the routine use of drainage after elective laparoscopic cholecystectomy justified? A randomized trial. J Laparoendosc Adv Surg Tech A. 2011;21:119-23.

222. El-Labban G, Hokkam E, El-Labban M, Saber A, Heissam K, El-Kammash S. Laparoscopic elective cholecystectomy with and without drain: A controlled randomised trial. J Minim Access Surg. 2012;8:90-2.

223. Lucarelli P, Picchio M, Martellucci J, Angelis F, Filippo A, Stipa F, et al. Drain after laparoscopic cholecystectomy for acute calculous cholecystitis. A pilot randomized study. Indian J Surg 2012; 74:1-5.

224. Picchio M, De Angelis F, Zazza S, Filippo AD, Mancini R, Pattaro G, et al. Drain after elective laparoscopic cholecystectomy. A randomized multicentre controlled trial. Surg Endosc 2012; 26: $2817-22$.

225. Shamim M. Routine Sub-hepatic Drainage versus No Drainage after Laparoscopic Cholecystectomy: Open, Randomized. Clinical Trial Indian J Surg. 2013;75:22-7.

226. Kim EY, Lee SH, Lee JS, Yoon YC, Park SK, Choi HJ, Yoo $\mathrm{DD}$, Hong TH. Is routine drain insertion after laparoscopic cholecystectomy for acute cholecystitis beneficial? A multicenter, prospective randomized controlled trial. J Hepatobiliary Pancreat Sci. 2015;22:551-7.

227. Park JS, Kim JH, Kim JK, Yoon DS. The role of abdominal drainage to prevent of intra-abdominal complications after laparoscopic cholecystectomy for acute cholecystitis: prospective randomized trial. Surg Endosc. 2015;29:453-7.

228. Sharma A, Gupta SN. Drainage versus no drainage after elective laparoscopic cholecystectomy. Kathmandu Univ Med J (KUMJ). 2016;14:69-72.

229. Prevot F, Fuks D, Cosse C, Pautrat K, Msika S, Mathonnet M, Khalil H, Mauvais F; FRENCH Cholecystitis Working Group, Regimbeau JM. The value of abdominal drainage after laparoscopic cholecystectomy for mild or moderate acute calculous cholecystitis: a post hoc analysis of a randomized clinical trial. World J Surg. 2016; 40: 2726-2734.

230. Belghiti J, Kabbej M, Sauvanet A, Vilgrain V, Panis Y, Fekete F. Drainage after elective hepatic resection. A randomized trial Ann Surg. 1993;218:748-53.

231. Fong Y, Brennan MF, Brown K, Heffernan N, Blumgart LH. Drainage is unnecessary after elective liver resection. Am J Surg. 1996;171:158-62.

232. Fuster J, Llovet JM, Garcia-Valdecasas JC, Grande L, Fondevila C, Vilana R, Palacin J, et al. Abdominal drainage after liver resection for hepatocellular carcinoma in cirrhotic patients: a randomized controlled study. Hepatogastroenterology. 2004;51:536-40.

233. Liu CL, Fan ST, Lo CM, Wong Y, Ng IO, Lam CM, Poon $\mathrm{RT}$, et al. Abdominal drainage after hepatic resection is contraindicated in patients with chronic liver diseases. Ann Surg. 2004;239:194-201.

234. Sun HC, Qin LX, Lu L, Wang L, Ye QH, Ren N, Fan J, et al. Randomized clinical trial of the effects of abdominal drainage after elective hepatectomy using the crushing clamp method. Br J Surg. 2006;93:422-6. 
235. Kim YI, Fujita S, Hwang VJ, Nagase Y. Comparison of abdominal drainage and no-drainage after elective hepatectomy: a randomized study. Hepatogastroenterology. 2014;61:707-11.

236. Conlon KC, Labow D, Leung D, Smith A, Jarnagin W, Coit DG, Merchant N, et al. Prospective randomized clinical trial of the value of intraperitoneal drainage after pancreatic resection. Ann Surg. 2001;234:487-93.

237. Van BurenBloomston GM 2nd, Hughes SJ, Winter J, Behrman $\mathrm{SW}$, Zyromski NJ, Vollmer C, et al. A randomized prospective multicenter trial of pancreaticoduodenectomy with and without routine intraperitoneal drainage. Ann Surg. 2014;259:605-12.

238. Witzigmann H, Diener MK, Kienkötter S, Rossion I, Bruckner T, Werner B, Pridöhl O, et al. No need for routine drainage after pancreatic head resection: the dual-center, randomized, controlled PANDRA trial (ISRCTN04937707). Ann Surg. 2016;264:528-37.

239. Haller JA Jr, Shaker IJ, Donahoo JS, Schnaufer L, White JJ. Peritoneal drainage versus non-drainage for generalized peritonitis from ruptured appendicitis in children: a prospective study. Ann Surg. 1973;177:595-600.

240. Stone HH, Hooper CA, Millikan WJ Jr. Abdominal drainage following appendectomy and cholecystectomy. Ann Surg. 1978;187:606-12.

241. Dandapat MC, Panda C. A perforated appendix: should we drain? J Indian Med Assoc. 1992;90:147-8.

242. Tander B, Pektas O, Bulut M. The utility of peritoneal drains in children with uncomplicated perforated appendicitis. Pediatr Surg Int. 2003;19:548-50.

243. Jani PG, Nyaga PN. Peritoneal drains in perforated appendicitis without peritonitis: a prospective randomized controlled study. East Cent Afr J Surg. 2011;16:62-71.

244. Magarey CJ, Chant AD, Rickford CR, Margarey JR. Peritoneal drainage and systemic antibiotics after appendicectomy. A prospective trial. Lancet. 1971;2:179-82.

245. Greenall MJ, Evans M, Pollock AV. Should you drain a perforated appendix? Br J Surg. 1978;65:880-2.

246. Merad F, Hay JM, Fingerhut A, Yahchouchi E, Laborde Y, Pélissier E, Msika S, Flamant Y. Is prophylactic pelvic drainage useful after elective rectal or anal anastomosis? A multicenter controlled randomized trial. French Association for Surgical Research. Surgery. 1999;125:529-35.

247. Brown SR, Seow-Choen F, Eu KW, Heah SM, Tang CL. A prospective randomised study of drains in infra-peritoneal rectal anastomoses. Tech Coloproctol. 2001;5:89-92.

248. Sagar PM, Hartley MN, Macfie J, Mancey-Jones B, Sedman P, May J. Randomized trial of pelvic drainage after rectal resection. Dis Colon Rectum. 1995;38:254-8.

249. Denost Q, Rouanet P, Faucheron JL, Panis Y, Meunier B, Cotte E, Meurette G, et al. To drain or not to drain infraperitoneal anastomosis after rectal excision for cancer: the GRECCAR 5 randomized trial. Ann Surg. 2017;265:474-80.

250. Hoffmann J, Shokouh-Amiri MH, Damm P, Jensen R. A prospective, controlled study of prophylactic drainage after colonic anastomoses. Dis Colon Rectum. 1987;30:449-52.

251. Johnson CD, Lamont PM, Orr N, Lennox M. Is a drain necessary after colonic anastomosis? J R Soc Med. 1989;82:661-4.

252. Sagar PM, Couse N, Kerin M, May J, MacFie J. Randomized trial of drainage of colorectal anastomosis. Br J Surg. 1993;80:769-71.

253. Merad F, Yahchouchi E, Hay JM, Fingerhut A, Laborde Y, Langlois-Zantain O. Prophylactic abdominal drainage after elective colonic resection and suprapromontory anastomosis: a multicenter study controlled by randomization. French Associations for Surgical Research. Arch Surg. 1998;133:309-14.
254. Shaffer D, Benotti PN, Bothe A Jr, Jenkins RL, Blackburn GL. A prospective, randomized trial of abdominal wound drainage in gastric bypass surgery. Ann Surg. 1987;206:134-7.

255. Baier PK, Glück NC, Baumgartner U, Adam U, Fischer A, Hopt UT. Subcutaneous Redon drains do not reduce the incidence of surgical site infections after laparotomy. A randomized controlled trial on 200 patients. Int J Colorectal Dis 2010; 25: 639-643.

256. Kaya E, Paksoy E, Ozturk E, Sigirli D, Bilgel H. Subcutaneous closed-suction drainage does not affect surgical site infection rate following elective abdominal operations: a prospective randomized clinical trial. Acta Chir Belg. 2010;110:457-62.

257. Numata M, Godai T, Shirai J, Watanabe K, Inagaki D, Hasegawa $\mathrm{S}$, Sato $\mathrm{T}$, et al. A prospective randomized controlled trial of subcutaneous passive drainage for the prevention of superficial surgical site infections in open and laparoscopic colorectal surgery. Int J Colorectal Dis. 2014;29:353-8.

258. Nakayama H, Takayama T, Okubo T, Higaki T, Midorikawa Y, Moriguchi M, Aramaki O, Yamazaki S. Subcutaneous drainage to prevent wound infection in liver resection: a randomized controlled trial. J Hepatobiliary Pancreat Sci. 2014;21:509-17.

259. Arer IM, Yabanoglu H, Aytac HO, Ezer A. The effect of subcutaneous suction drains on surgical site infection in open abdominal surgery A prospective randomized study. Ann Ital Chir. 2016;87:49-55.

260. Watanabe J, Ota M, Kawamoto M, Akikazu Y, Suwa Y, Suwa H, Momiyama M, et al. A randomized controlled trial of subcutaneous closed-suction Blake drains for the prevention of incisional surgical site infection after colorectal surgery. Int J Colorectal Dis. 2017;32:391-8.

261. Wetter LA, Dinneen MD, Levitt MD, Motson RW. Controlled trial of polyglycolic acid versus catgut and nylon for appendicectomy wound closure. Br J Surg. 1991;78:985-7.

262. Pauniaho SL, Lahdes-Vasama T, Helminen MT, Iber T, Mäkelä E, Pajulo O. Non-absorbable interrupted versus absorbable continuous skin closure in pediatric appendectomies. Scand J Surg. 2010;99:142-6.

263. Kotaluoto S, Pauniaho SL, Helminen M, Grun P, Kao TH. Wound healing after open appendectomies in adult patients: a prospective, randomised trial comparing two methods of wound closure. World J Surg. 2012;36:2305-10.

264. Koskela A, Kotaluoto S, Kaartinen I, Pauniaho SL, Rantanen T, Kuokkanen H. Continuous absorbable intradermal sutures yield better cosmetic results than nonabsorbable interrupted sutures in open appendectomy wounds: a prospective, randomized trial. World J Surg. 2014;38:1044-50.

265. Tanaka A, Sadahiro S, Suzuki T, Okada K, Saito G. Randomized controlled trial comparing subcuticular absorbable suture with conventional interrupted suture for wound closure at elective operation of colon cancer. Surgery. 2014;155:486-92.

266. Andrade LA, Muñoz FY, Báez MV, Collazos SS, de Los Angeles Martinez Ferretiz M, Ruiz B, Montes O, et al. Appendectomy skin closure technique, randomized controlled trial: changing paradigms (ASC). World J Surg. 2016;40:2603-10.

267. Hopkinson GB, Bullen BR. Removable subcuticular skin suture in acute appendicitis: a prospective comparative clinical trial. $\mathrm{Br}$ Med J (Clin Res Ed). 1982;284:869.

268. Anatol TI, Roopchand R, Holder Y, Shing-Hon G. A comparison of the use of plain catgut, skin tapes and polyglactin sutures for skin closure:a prospective clinical trial. J R Coll Surg Edinb. 1997;42:124-7.

269. Richards PC, Balch CM, Aldrete JS. Abdominal wound closure. A randomized prospective study of 571 patients comparing continuous vs. interrupted suture techniques. Ann Surg. 1983;197:238-43. 
270. McNeil PM, Sugerman HJ. Continuous absorbable vs interrupted nonabsorbable fascial closure. A prospective, randomized comparison. Arch Surg. 1986;121:821-3.

271. Wissing J, van Vroonhoven TJ, Schattenkerk ME, Veen HF, Ponsen RJ, Jeekel J. Fascia closure after midline laparotomy:results of a randomized trial. Br J Surg. 1987;74:738-41.

272. Sahlin S, Ahlberg J, Granström L, Ljungström KG. Monofilament versus multifilament absorbable sutures for abdominal closure. Br J Surg. 1993;80:322-4.

273. Derzie AJ, Silvestri F, Liriano E, Benotti P. Wound closure technique and acute wound complications in gastric surgery for morbid obesity:a prospective randomized trial. J Am Coll Surg. 2000;191:238-43.

274. Brolin RE. Prospective, randomized evaluation of midline fascial closure in gastric bariatric operations. Am J Surg. 1996;172:328-31.

275. Lewis RT, Wiegand FM. Natural history of vertical abdominal parietal closure: Prolene versus Dexon. Can J Surg. 1989;32:196-200.

276. Seiler CM, Bruckner T, Diener MK, Papyan A, Golcher H, Seidlmayer C, Franck A, et al. Interrupted or continuous slowly absorbable sutures for closure of primary elective midline abdominal incisions: a multicenter randomized trial (INSECT: ISRCTN24023541). Ann Surg. 2009;249:576-82.

277. Tsujinaka T, Yamamoto K, Fujita J, Endo S, Kawada J, Nakahira S, Shimokawa T, et al. Subcuticular sutures versus staples for skin closure after open gastrointestinal surgery:a phase 3, multicentre, open-label, randomised controlled trial. Lancet. 2013;382:1105-12.

278. Kobayashi S, Ito M, Yamamoto S, Kinugasa Y, Kotake M, Saida Y, Kobatake T, et al. Randomized clinical trial of skin closure by subcuticular suture or skin stapling after elective colorectal cancer surgery. Br J Surg. 2015;102:495-500.

279. Maartense S, Bemelman WA, Dunker MS, de Lint C, Pierik EG, Busch OR, Gouma DJ. Randomized study of the effectiveness of closing laparoscopic trocar wounds with octylcyanoacrylate, adhesive papertape or poliglecaprone. Br J Surg. 2002;89:1370-5.

280. Matin SF. Prospective randomized trial of skin adhesive versus sutures for closure of 217 laparoscopic port-site incisions. J Am Coll Surg. 2003;196:45-853.

281. Sebesta MJ, Bishoff JT. Octylcyanoacrylate skin closure in laparoscopy. JSLS. 2004;8:9-14.

282. Dowson CC, Gilliam AD, Speake WJ, Lobo DN, Beckingham IJ. A prospective, randomized controlled trial comparing n-butyl cyanoacrylate tissue adhesive (LiquiBand) with sutures for skin closure after laparoscopic general surgical procedures. Surg Laparosc Endosc Percutan Tech. 2006;16:146-50.

283. Chen K, Klapper AS, Voige H, Del Priore G. A randomized, controlled study comparing two standardized closure methods of laparoscopic port sites. JSLS. 2010;14:391-4.

284. Jallali N, Haji A, Watson CJ. A prospective randomized trial comparing 2-octyl cyanoacrylate to conventional suturingin closure of laparoscopic cholecystectomy incisions. J Laparoendosc Adv Surg Tech A. 2004;14:209-11.

285. Anderson AD, McNaught CE, MacFie J, et al. Randomized clinical trial of multimodal optimization and standard perioperative surgical care. Br J Surg 2003; 90:1497-1504. PMID14648727

286. Gatt M, Anderson AD, Reddy BS, et al. Randomized clinical trial of multimodal optimization of surgical care in patients undergoing major colonic resection. Br J Surg 2005; 92:1354-1362. PMID16237744

287. Delaney CP, Zufshi M, Senagore AJ, et al. Prospective, randomized controlled trial between a pathway of controlled rehabilitation with early ambulation and diet and traditional postoperative care after laparotomy and intestinal resection. Dis Colon Rectum 2003; 46:851-859. PMID12847356

288. Ionescu D, Iancu C, Iron D, et al. Implementing fast-track protocol for colorectal surgery: a prospective randomized clinical trial. World J Surg 2009; 33: 2433-2438. PMID19707815

289. Serclova Z, Dytrych P, Marvan J, et al. Fast-track in open intestinal surgery: prospective randomized study (clinical trials gov identifier no. NCT00123456). Clin Nutr 2009; 28:618-624. PMID19535182

290. Muller S, Zalunardo MP, Hubner M, et al. A fast-track program reduces complications and length of hospital stay after open colonic surgery. Gastroenterology 2009; 136:842-847. PMID19135997

291. Wang D, Kong Y, Zhong B, et al. Fast-track surgery improves postoperative recovery in patients with gastric cancer: a randomized comparison with conventional postoperative care. J Gastrointest Surg 2010; 14:620-627. PMID20108171

292. Garcia-Botello S, Canovas de Lucas R, et al. Implementation of a perioperative multimodal rehabilitation protocol in elective colorectal surgery. A prospective randomized controlled study. Cir Esp 2011; 89:159-166. PMID21345423

293. Wang G, Jiang ZW, Xu J, et al. Fast-track rehabilitation program vs conventional care after colorectal resection: a randomized clinical trial. World J Gastroenterol 2011; 17: 671-676. PMID21350719

294. Vlug MS, Wind J, Holmann MW, et al. Laparoscopy in combination with fast track multimodal management is the best perioperative strategy in patients undergoing colonic surgery. Ann Surg 2011; .254:868-875. PMID21597360

295. Ren L, Zhu D, Wei Y, et al. Enhanced recovery after surgery (ERAS) program attenuates stress and accelerates recovery in patients after radical resection for colorectal cancer: a prospective randomized controlled trial. World J Surg 2012; 36:407-414. PMID22102090

296. Kim JW, Kim WS, Cheong JH, et al. Safety and efficacy of fast-track surgery in laparoscopic distal gastrectomy for gastric cancer: a randomized clinical trial. World J Surg 2012; 36:2879_ 2887. PMID22941233

297. Yang D, He W, Zhang S, et al. Fast-track surgery improves postoperative clinical recovery and immunity after elective surgery for colorectal carcinoma: randomized controlled clinical trial. World J Surg 2012; 36:1874-1880. PMID22526050

298. Wang G, Jiang Z, Zhao K, et al. Immunologic response after laparoscopic colon cancer operation within an enhanced recovery program. J Gastrointest Surg 2012; 16:1379-1388. PMID22585532

299. Ni CY, Yang Y, Chang YQ, et al. Fast-track surgery improves postoperative recovery in patients undergoing partial hepatectomy for primary liver cancer: A prospective randomized controlled trial. Eur J Surg Oncol. 2013;39:542-7 (PMID 23562361)

300. Lee SM, Kang SB, Jang JH, et al. Early rehabilitation versus conventional care after laparocopic rectal surgery: a prospective, randomized, controlled trial. Surg Endosc. 2013;27:3902-9 (PMID 23708720).

301. Feng F, Ji G, Li JP, et al. Fast-track surgery could improve postoperative recovery in radical total gastrectomy patients. World $\mathrm{J}$ Gastroenterol. 2013;19:3642-8 (PMID 23801867).

302. Nanavanti AJ, Prabhakar S. A comparative study of "fast-track" versus traditional peri-operative care protocol in gastrointestinal surgeries. J Gastrointest Surg. 2014;18:757-67 (PMID 24222323)

303. Jia Y, Jin G, Guo S, et al. Fast-track surgery decreases the incidence of postoperative delirium and other complications in elderly patients with colorectal carcinoma. Langenbecks Arch Surg. 2014;399:77-84 (PMID 24337734). 
304. Zhao G, Cao S, Cui J. Fast-track surgery improves postoperative clinical recovery and reduces postoperative insulin resistance after esophagectomy for esophageal cancer. Support Care Cancer. 2014;22:351-8 (PMID 24068549).

305. Feng F, Li XH, Shi H, et al. Fast-track surgery combined with laparoscopic could improve postoperative recovery of low-risk rectal cancer patients: a randomized controlled clinical trial. J Dig Dis. 2014; 15:306-13 (PMID 24597608).

306. Liu XX, Jiang ZW, Wang ZM, et al. Multimodal optimization of surgical care shows beneficial outcome in gastrectomy surgery. JPEN J Parenter Enteral Nutr. 2010;34:313-21 (PMID 20467014).

307. Liu G, Jian F, Wang X, et al. Fast-track surgery protocol in elderly patients undergoing laparoscopic radical gastrectomy: a randomized controlled trial. Onco Targets Ther. 2016;2016:3345-51 (PMID 27330314).

308. Chen L, Sun L, Lang Y, et al. Fast-track surgery improves postoperative clinical recovery and cellular and humoral immunity after esophagectomy for esophageal cancer. BMC Cancer. 2016;16:449 (PMID 27401305).

309. Wang Q, Suo J, Jiang J, et al. Effectiveness of fast-track rehabilitation vs conventional care in laparoscopic colorectal resection for elderly patients: a randomized trial. Colerectal Dis. 2012;14:1009-13 (PMID 21985126).

310. Bu J, Lin N, Huang X, et al. Feasibility of fast-track surgery in elderly patients with gastric cancer. J Gastrointest Surg. 2015;19:1391-8 (PMID 25943912).

311. Abdikarim I, Cao XY, Li SZ, et al. Enhanced recovery after surgery with laparoscopic radical gastrectomy for stomach carcinomas. World J Gastroenterol. 2015;21:1339-44 (PMID 26715818).

312. Hu CH, Jiang LX, Zheng HT, et al. Preliminary experience of fast-track surgery combined with laparoscopy-assisted radical distal gastrectomy for gastric cancer. J Gastrointest Surg. 2012;16:1830-9 (PMID 22854954).

313. Jones C, Kelliher L, Dickinson M, et al. Randomized clinical trial on enhanced recovery versus standard care following open liver resection. Br J Surg. 2013;100:1015-24 (PMID 23696477).

314. Grant MC, Yang D, Wu CL, et al. Impact of enhanced recovery after surgery and fast track surgery pathway on Healthcareassociated infections: results from a systematic review and metaanalysis. Ann Surg. 2017;265:68-79 (PMID 28009729).

315. Gianotti L, Biffi R, Sandini M, et al. Preoperative oral carbohydrate load versus placebo in major elective abdominal surgery (PROCY): a randomized placebo-controlled, multicenter, phase III trial. Ann Surg. 2017;267:623 (PMID 28582271).

316. Hausel J, Nygren J, Thorell A, et al. Randomized clinical trial of the effects of oral preoperatively carbohydrates on postoperative nausea and vomiting after laparoscopic cholecystectomy. Br J Surg. 2005;92:415-21 (PMID 15739210).

317. Mathur S, Plank LD, McCall JL, et al. Randomized controlled trial of preoperative oral carbohydrate treatment in major abdominal surgery. Br J Surg. 2010;97:485-94 (PMID 20205227).

318. Noblett SE, Watson DS, Huong H, et al. Pre-operative oral carbohydrate loading in colorectal surgery: a randomized controlled trial. Colorectal Dis. 2006;8:563-9 (PMID 16919107).

319. Pedziwiatr M, Pisarska M, Matlok M, et al. Randomized clinical trial to compare the effects of preoperative oral carbohydrate loading versus placebo on insulin resistance and cortisol level after laparoscopic cholecystectomy. Pol Przegl Chir. 2015;87:402-8 (PMID 26495916).

320. Yuill KA, Richardson RA, Davidson HI, et al. The administration of an oral carbohydrate-containing fluid prior to major elective upper gastrointestinal surgery preserves skeletal muscle mass postoperatively - a randomized clinical trial. Clin Nutr. 2005;24:32-8 (PMID 15681099).
321. Kaska M, Grosmanova T, Havel E, et al. The impact and safety of preoperative oral or intravenous carbohydrate administration versus fasting in colorectal surgery- a randomized controlled trial. Wien Klin Wochenschr. 2010;122:23-30 (PMID 20177856).

322. Fujikuni N, Tanabe K, Tokumoto N, et al. World J Gastrointest Surg 2016; 8:382-388. (PMID 27231517)

323. Awad S, Varadhan KK, Ljungqvist O, et al. A meta-analysis of randomized controlled trials on preoperative oral carbohydrate treatment in elective surgery. Clin Nutr. 2013;32:34-44 (PMID 23200124).

324. Ban KA, Minei JP, Laronga C, et al. American college of Surgeons and Surgical Infection Society: surgical site infection guidelines, 2016 Update. J Am Coll Surg. 2016;224:59-74 (PMID 27915053).

325. Berrios-Torres SI, Umscheid CA, Bratzler DW, et al. Centers for disease control and prevention guideline for the prevention of surgical site infection, 2017. JAMA Surg. 2017;152:784-91 (PMID 28467526).

326. Cao SG, Ren JA, Shen B, et al. Intensive versus conventional insulin therapy in type diabetes patients undergoing D2 gastrectomy for gastric cancer: a randomized controlled trial. World J Surg. 2011;35:85-92 (PMID 20878324).

327. Cao S, Zhou Y, Chen D, et al. Intensive versus conventional insulin therapy in nondiabetic patients receiving parenteral nutrition after undergoing D2 gastrectomy for gastric cancer: a randomized controlled trial. J Gastrointest Surg. 2011;15:1961-8 (PMID 21904964).

328. Okabayashi T, Shima Y, Sumiyoshi T, et al. Intensive versus intermediate glucose control in surgical intensive care unit patients. Diabetes Care. 2014;37:1516-24 (PMID 24623024).

329. Yuan J, Liu T, Zhang X, et al. Intensive versus conventional glycemic control in patients with diabetes during enteral nutrition after gastrectomy. J Gastrointest Surg. 2015;19:1553-8 (PMID 26084869).

330. Kwon S, Thompson R, Dellinger P, et al. Importance of perioperative glycemic control in general surgery: a report from the surgical care and outcomes assessment program. Ann Surg. 2013;257:8-14 (PMID 23235393).

331. Kiran RP, Turina M, Hammel J, et al. The clinical significance of a elevated postoperative glucose value in nondiabetic patients after colorectal surgery: evidence for the need for tight glucose control. Ann Surg. 2013;258:599-605 (PMID 23979274).

332. Jeon CY, Furuya EY, Berman MF, et al. The role of pre-operative and post-operative glucose control in surgical site infections and mortality. PLoS ONE. 2012; 7:e45616 (PMID 23029136).

333. de Vries FE, Gans SL, Solomkin JS, et al. Meta-analysis of lower perioperative blood glucose target levels for reduction of surgical-site infection. Br J Surg. 2017;104:e95-105 (PMID 27901264)

334. Sato Y, Motoyama S, Takano H, et al. Esophageal cancer patients have a high incidence of severe periodontitis and preoperative dental care reduced the likelihood of severe pneumonia after esophagectomy. Dig Surg. 2016;33:495-502 (PMID 2728475).

335. Kurz A, Sessler DI, Lenhardt R. Perioperative normothermia to reduce the incidence of surgical-wound infection and shorten hospitalization. Study of Wound Infection and Temperature Group. N Engl J Med. 1996;334:1209-15.

336. Melling AC, Ali B, Scott EM, et al. Effects of preoperative warming on the incidence of wound infection after clean surgery: a randomised controlled trial. Lancet. 2001;358:876-80.

337. Greif R, Akca O, Horn EP, et al. Supplemental perioperative oxygen to reduce the incidence of surgical-wound infection. $\mathrm{N}$ Engl J Med. 2000;342(3):161-7.

338. Pryor KO, Fahey TJ 3rd, Lien CA, et al. Surgical site infection and the routine use of perioperative hyperoxia in a general 
surgical population: a randomized controlled trial. JAMA. 2004;291(1):79-87.

339. Belda FJ, Aguilera L, García de la Asunción J, et al. Supplemental perioperative oxygen and the risk of surgical wound infection: a randomized controlled trial. JAMA. 2005;294(16):2035-42.

340. Mayzler O, Weksler N, Domchik S, et al. Does supplemental perioperative oxygen administration reduce the incidence of wound infection in elective colorectal surgery? Minerva Anestesiol. 2005;71(1-2):21-5.

341. Myles PS, Leslie K, Chan MTV, et al. Avoidance of nitrous oxide for patients undergoing major surgery: a randomized controlled trial. Anesthesiology. 2007;107(2):221-31.

342. Meyhoff CS, Wetterslev J, Jorgensen LN, et al. Effect of high perioperative oxygen fraction on surgical site infection and pulmonary complications after abdominal surgery: the PROXI randomized clinical trial. JAMA. 2009;302(14):1543-50.

343. Bickel A, Gurevits M, Vamos R, et al. Perioperative hyperoxygenation and wound site infection following surgery for acute appendicitis: a randomized, prospective, controlled trial. Arch Surg. 2011;146(4):464-70.

344. Schietroma M, Cecilia EM, Carlei F, et al. Prevention of anastomotic leakage after total gastrectomy with perioperative supplemental oxygen administration: a prospective randomized, double-blind, controlled, single-center trial. Ann Surg Oncol. 2013;20(5):1584-90.

345. Kurz A, Fleischmann E, Sessler DI, et al. Effects of supplemental oxygen and dexamethasone on surgical site infection: a factorial randomized trial. Br J Anaesth. 2015;115:434-43 (PMID: 25900659).

346. Schietroma M, Pessia B, Colozzi S, et al. Effect of high perioperative oxygen fraction on surgical site infection following surgery for acute sigmoid diverticulitis. A prospective, randomized, double blind, controlled, monocentric trial. Chirurgia (Bucur). 2016;111(3):242-50.

347. Stewart BT, Woods RJ, Collopy BT, et al. Early feeding after elective open colorectal resections: a prospective randomized trial. Aust N Z J Surg. 1998;68:125-8.

348. El Nakeeb A, Fikry A, El Metwally T, et al. Early oral feeding in patients undergoing elective colonic anastomosis. Int J Surg. 2009;7:206-9.

349. da Fonseca LM, Profeta da Luz MM, Lacerda-Filho A, et al. A simplified rehabilitation program for patients undergoing elective colonic surgery—randomized controlled clinical trial. Int $\mathbf{J}$ Colorectal Dis. 2011;26:609-16.

350. Barlow R, Price P, Reid TD, et al. Prospective multicentre randomised controlled trial of early enteral nutrition for patients undergoing major upper gastrointestinal surgical resection. Clin Nutr. 2011;30:560-6.

351. Dag A, Colak T, Turkmenoglu O, et al. A randomized controlled trial evaluating early versus traditional oral feeding after colorectal surgery. Clinics (Sao Paulo). 2011;66:2001-5.

352. Klappenbach RF, Yazyi FJ, Alonso Quintas F, et al. Early oral feeding versus traditional postoperative care after abdominal emergency surgery: a randomized controlled trial. World J Surg. 2013;37:2293-9.

353. Pragatheeswarane M, Muthukumarassamy R, Kadambari D, et al. Early oral feeding vs traditional feeding in patients undergoing elective open bowel surgery-a randomized controlled trial. J Gastrointest Surg. 2014;18:1017-23.

354. Gardezi SA, Chaudhary AM, Sial GA, Ahmad I, Rashid M. Role of "polyurethane membrane" in post operative wound management. J Pak Med Assoc. 1983;33:219-22.

355. Persson M, Svenberg T, Poppen B. To dress or not to dress surgical wounds? Patients' attitudes to wound care after major abdominal operations. Eur J Surg. 1995;161:791-3.

356. Holm C, Petersen JS, Grønboek F, Gottrup F. Effects of occlusive and conventional gauze dressings on incisional healing after abdominal operations. Eur J Surg. 1998;164:179-83.

357. Shinohara T, Yamashita Y, Satoh K, Mikami K, Yamauchi Y, Hoshino S, Noritomi A, Maekawa T. Prospective evaluation of occlusive hydrocolloid dressing versus conventional gauze dressing regarding the healing effect after abdominal operations: randomized controlled trial. Asian J Surg. 2008;31:1-5.

358. Krieger BR, Davis DM, Sanchez JE, Mateka JJ, Nfonsam VN, Frattini JC, Marcet JE. The use of silver nylon in preventing surgical site infections following colon and rectal surgery. Dis Colon Rectum. 2011;54:1014-9.

359. Siah CJ, Yatim J. Efficacy of a total occlusive ionic silver-containing dressing combination in decreasing risk of surgical site infection: an RCT. J Wound Care. 2011;20:561-8.

360. Biffi R, Fattori L, Bertani E, Radice D, Rotmensz N, Misitano P, Cenciarelli $\mathrm{S}$, et al. Surgical site infections following colorectal cancer surgery: a randomized prospective trial comparing common and advanced antimicrobial dressing containing ionic silver. World J Surg Oncol. 2012;10:94.

361. Ruiz-Tovar J, Llavero C, Morales V, Gamallo C. Total occlusive ionic silver-containing dressing vs mupirocin ointment application vs conventional dressing in elective colorectal surgery: effect on incisional surgical site infection. J Am Coll Surg. 2015;221:424-9.

362. Selvaggi F, Pellino G, Sciaudone G, Corte AD, Candilio G, Campitiello F, Canonico S. New advances in negative pressure wound therapy (NPWT) for surgical wounds of patients affected with Crohn's disease. Surg Technol Int. 2014;24:83-9.

363. Shen P, Blackham AU, Lewis S, Clark CJ, Howerton R, Mogal HD, Dodson RM, et al. Phase II randomized trial of negativepressure wound therapy to decrease surgical site infection in patients undergoing laparotomy for gastrointestinal, pancreatic, and peritoneal surface malignancies. J Am Coll Surg. 2017;224:726-37.

364. O'Leary DP, Peirce C, Anglim B, Burton M, Concannon E, Carter M, Hickey K, Coffey JC. Prophylactic negative pressure dressing use in closed laparotomy wounds following abdominal operations: a randomized, controlled, open-label trial: the PICO trial. Ann Surg. 2017;265:1082-6.

365. Li PY, Yang D, Liu D, Sun SJ, Zhang LY. Reducing surgical site infection with negative-pressure wound therapy after open abdominal surgery: a prospective randomized controlled study. Scand J Surg. 2017;106:189-95.

Publisher's Note Springer Nature remains neutral with regard to jurisdictional claims in published maps and institutional affiliations. 


\section{Affiliations}

Hiroki Ohge ${ }^{1} \cdot$ Toshihiko Mayumi $^{2} \cdot$ Seiji Haji $^{3} \cdot$ Yuichi Kitagawa $^{4} \cdot$ Masahiro Kobayashi $^{5} \cdot$ Motomu Kobayashi $^{6}$. Toru Mizuguchi ${ }^{7}$. Yasuhiko Mohri ${ }^{8}$. Fumie Sakamoto ${ }^{9}$. Junzo Shimizu ${ }^{10} \cdot$ Katsunori Suzuki $^{11} \cdot$ Motoi Uchino $^{12}$. Chizuru Yamashita ${ }^{13}$. Masahiro Yoshida ${ }^{14} \cdot$ Koichi Hirata $^{15}$. Yoshinobu Sumiyama ${ }^{16}$. Shinya Kusachi ${ }^{17} \cdot$ The $^{2}$ Committee for Gastroenterological Surgical Site Infection Guidelines, the Japan Society for Surgical Infection

1 Department of Infectious Diseases, Hiroshima University Hospital, Hiroshima, Japan

2 Department of Emergency Medicine, School of Medicine, University of Occupational and Environmental Health, Fukuoka, Japan

3 Department of Surgery, Soseikai General Hospital, Kyoto, Japan

4 Department of Infection Control, National Center for Geriatrics and Gerontology, Aichi, Japan

5 Laboratory of Clinical Pharmacokinetics, School of Pharmacy, Kitasato University, Tokyo, Japan

6 Perioperative Management Center, Department of Anesthesiology and Resuscitology, Okayama University Hospital, Okayama, Japan

7 Division of Surgical Science, Department of Nursing, Sapporo Medical University, Sapporo, Japan

8 Department of Surgery, Mie Prefectural General Medical Center, Mie, Japan

9 Infection Control Division, Quality Improvement Center, St. Luke's International Hospital, Tokyo, Japan
10 Department of Surgery, Toyonaka Municipal Hospital, Osaka, Japan

11 Division of Infection Control and Prevention, University of Occupational and Environmental Health, Fukuoka, Japan

12 Division of Inflammatory Bowel Disease Surgery, Department of Gastroenterological Surgery, Hyogo College of Medicine, Hyogo, Japan

13 Department of Anesthesiology and Critical Care Medicine, Fujita Health University School of Medicine, Aichi, Japan

14 Department of Hepato-Biliary-Pancreatic and Gastrointestinal Surgery, International University of Health and Welfare, School of Medicine, Chiba, Japan

15 JR Sapporo Hospital, Sapporo, Japan

16 Toho University, Tokyo, Japan

17 Department of Surgery, Tohokamagaya Hospital, Chiba, Japan 